University of Zurich

Department of Economics

Working Paper Series

ISSN 1664-7041 (print)

ISSN 1664-705X (online)

Working Paper No. 315

\title{
On self-serving strategic beliefs
}

Nadja R. Ging-Jehli, Florian H. Schneider and Roberto A. Weber

January 2019 


\title{
On self-serving strategic beliefs
}

\author{
Nadja R. Ging-Jehli \\ The Ohio State University
}

\author{
Florian H. Schneider \\ University of Zurich
}

Roberto A. Weber
University of Zurich

January 23, 2019*

\begin{abstract}
We experimentally study settings where an individual may have an incentive to adopt negative beliefs about another's intentions in order to justify egoistic behavior. Our first study uses a game in which a player can take money from an opponent in order to prevent the opponent from subsequently causing harm. We hypothesize that players will justify taking by engaging in "strategic cynicism," convincing themselves of the opponent's ill intentions. We elicit incentivized beliefs both from players with such an incentive and from neutral third parties with no incentive to bias their beliefs. We find no difference between the two sets of beliefs, suggesting that people do not negatively bias their beliefs about a strategic opponent even when they have an incentive to do so. This result contrasts with Di Tella, et al. (2015), who argue that they provide evidence of strategic cynicism. We reconcile the discrepancy by using Di Tella, et al.'s, data, a simple model of strategic belief manipulation and a novel experiment in which we replicate Di Tella, et al.'s, experiment and also elicit the beliefs of neutral third parties. Across three experimental datasets, the results provide no evidence of negatively biased beliefs about others' intentions. However, Di Tella, et al.'s, results and our novel data indicate that those with a greater incentive to view others' intentions negatively exhibit relatively less positive beliefs than those without such incentives.
\end{abstract}

Keywords: motivated beliefs, strategic cynicism, bias, experiment

JEL codes: C72, D83, C92

\footnotetext{
* Corresponding author: Roberto Weber, Department of Economics, University of Zurich, Blümlisalpstrasse 10, 8006 Zürich, Switzerland, roberto.weber@econ.uzh.ch. We thank participants at the 2015 Self-Deception, SelfSignaling and Self-Control Workshop in Toulouse, the 2016 CUSO Workshop in Freiburg, the 2016 Zurich Workshop in Economics, the Barcelona GSE seminar and the 2018 CESifo Behavioural Economics Conference. We thank Roland Bénabou, Botond Köszegi, Ricardo Perez-Truglia, Martin Schonger, Ivo Schurtenberger and Christian Zehnder for valuable comments.
} 


\section{Introduction}

Considerable evidence indicates that decision makers confronted with tradeoffs between egoistic and social considerations, such as fairness and equality, will rely on justifications to prioritize the former while avoiding the impression that they are acting selfishly (Dana, Weber and Kuang, 2007; Hamman, Loewenstein and Weber, 2010; Gino, Norton and Weber, 2016; Grossman and van der Weele, 2017). This includes engaging in self-serving belief manipulation, whereby actions that are personally beneficial can be justified by changing one's beliefs or perceptions of what is fair (Babcock and Loewenstein, 1997; Konow, 2000), a product's quality (Chen \& Gesche, 2017; Gneezy, Saccardo, SerraGarcia, and van Veldhuizen, 2018) or the likely outcomes of a random process (Haisley and Weber, 2010; Exley, 2016). ${ }^{1}$

One important, but largely unexplored, context for self-serving belief manipulation is in strategic settings where individuals form beliefs about an opponent's likely behavior. It has long been recognized that beliefs about other players' actions and intentions can play a central role in prosocial behavior, with a positive relationship between the belief that others will act unkindly and one's own egoistic behavior (e.g., Rabin, 1993; Levine, 1998; Fischbacher, Gächter and Fehr, 2001). Strategic beliefs are typically assumed to be determined by the structure of the game and beliefs about others' preferences or rationality. However, in light of the apparent ease with which people bias their beliefs in self-serving ways in other contexts, it seems plausible that they may similarly bias their beliefs about others' actions when doing so can justify acting in a selfish way that harms others. ${ }^{2}$ Indeed, a recent paper by Di Tella, Perez-Truglia, Babino and Sigman (2015) provides evidence consistent with the idea that people engage in such "strategic cynicism." Specifically, they

\footnotetext{
${ }^{1}$ Such self-serving interpretations are related to the concept of "motivated reasoning" from psychology (Kunda, 1990). Models introducing self-deception and self-image concerns to economics include Akerlof and Dickens (1982), Rabin (1994), Akerlof and Kranton (2000), Bénabou and Tirole (2006, 2011), Bénabou (2013). There is also evidence for self-serving belief manipulation about other desired qualities, like one's abilities (Möbius, Niederle, Niehaus and Rosenblat, 2017; Zimmerman, 2018), beauty (Eil and Rao, 2011), honesty (Mazar, Amir, and Ariely 2008; Shalvi, Gino, Barkan, and Ayal, 2015) and about desired future life events (Irwin, 1953; Mayraz, 2013).

${ }^{2}$ There are many contexts in which adopting cynical beliefs about others' likely actions may be strategically desirable for an individual constrained to act morally. For instance, an employer who can benefit by laying off a worker may find it easier to do so if she adopts the belief that the employee is likely committing acts that merit firing. A national leader intent on seizing land from a neighboring country may find this easier to justify under the belief that the other country intends to act aggressively. A US President may find it easier to justify firing a special counsel investigating him for misconduct if he convinces himself that the investigation is a WITCH HUNT! Trivers (2011) discusses an alternative motive to engage in self-deception in strategic situations: deceiving oneself about one's own qualities, such as ability, might be an effective strategy to deceive others (see also Schwardmann and van der Weele (2016), for related experimental evidence).
} 
demonstrate that people with a greater opportunity to take from another person believe that this opponent is more likely to act in a greedy and harmful manner.

Our study investigates the phenomenon of strategic self-deception, although we initially approach this question in a different manner from Di Tella, et al. Rather than testing whether people with a greater incentive to take from others adopt relatively more negative beliefs about these opponents, as they do, our focus is on whether people with the opportunity to take from others adopt beliefs that are biased in comparison to two reasonable objective standards: the actual empirical behavioral frequency of opponents' behavior and the beliefs of neutral outsiders with no incentive to view others self-servingly. That is, we test the extent to which individuals with an incentive to engage in strategic cynicism adopt beliefs that are negatively biased in absolute terms. In contrast, Di Tella, et al., study a relative form of this bias, investigating whether one group's beliefs are more negative—or, critically, less positive - than those of another group.

Our results show that this distinction is important. We find evidence consistent with the relative bias documented by Di Tella, et al. However, we also show in two novel studies and in Di Tella, et al.'s, own data that there is no evidence of negatively biased strategic beliefs in absolute terms. In fact, across all three studies, individuals with an incentive to take from others - and, therefore, with an incentive to engage in strategic cynicism-actually hold highly accurate beliefs that are close to both the actual behavior of their counterparts and to the beliefs of neutral observers. The only bias, relative to these objective and neutral standards, in all three data sets lies in the beliefs of individuals in Di Tella, et al.'s, design with a low ability to take from their counterpart; these people exhibit overly positive beliefs about their counterpart's likely action. Thus, to the extent that absolute bias exists in people's beliefs about a counterpart's actions, it appears to be one of positivity rather than cynicism.

Our first study, which we conducted prior to knowing about Di Tella, et al.'s, related work, uses a game that we refer to as the "pre-emptive taking game." In this game, a pair of players - say, "Ann" and "Bob" - both start off with the same wealth endowment. Ann first decides how much to take from Bob. Bob then decides how much to take from Ann. A key feature is that Bob's ability to take from Ann increases in the amount of money he has remaining after Ann's taking decision. That is, by taking from Bob, Ann both increases her earnings and reduces his opportunity to act in a selfish and harmful manner. Thus, Ann's taking decision may naturally be influenced by whether or not she thinks Bob will use his remaining money to harm Ann. But, if Ann feels constrained to act "fairly," the game also 
creates an incentive for Ann to manipulate her beliefs about Bob's likely action, since this gives her a justification for taking more under the guise of self-protection.

Our main purpose in this study is to test for a bias in the beliefs of subjects in the role of Ann. Therefore, we directly elicit such beliefs about the amount that Bob will take if given the opportunity. We compare this to beliefs elicited from neutral third parties who have no incentive to engage in strategic cynicism. Our hypothesis is that Ann's incentive to justify taking by adopting a cynical belief about Bob's likely behavior will lead her to self-servingly negatively bias these beliefs. Surprisingly, however, in light of other instances in which people seem to engage in self-deception in non-strategic contexts, we find no difference between the two sets of beliefs. The two beliefs are virtually identical and very close to the true empirical frequencies. This suggests, at the least, that there are limitations in people's ability to manipulate their beliefs about a strategic opponent.

This finding also contrasts with those of Di Tella, et al., who argue that their experimental evidence shows that individuals form biased beliefs and convince themselves that their counterparts are more likely act egoistically than they actually are. ${ }^{3}$ Di Tella, et al., support this conclusion with an experiment using a game, labeled the "corruption game," that shares features with our pre-emptive taking game. In this game, Ann and Bob again start with an identical number of tokens and Ann similarly decides how many tokens to take from Bob. In the corruption game, however, Bob simultaneously makes a binary decision whether to act "corruptly," by taking a side payment that increases Bob's wealth while lowering the value of the tokens. Thus, Ann can justify taking more tokens from Bob as a fair action if she thinks that he will act corruptly. The experiment manipulates Ann's ability to take tokens from Bob and finds that subjects in the role of Ann adopt more pessimistic beliefs when they have the ability to take more tokens. Thus, individuals seem to respond to the incentive to take more from their counterpart by engaging in strategic cynicism.

At first, these two results seem to offer conflicting evidence. Our first study finds no evidence of strategic cynicism. In contrast, Di Tella, et al., conclude that people engage in self-serving belief manipulation. We reconcile this apparent inconsistency using the data from Di Tella, et al.'s, experiment, a simple model of strategic self-deception and an additional novel experiment. We show that the two sets of results are actually highly

\footnotetext{
${ }^{3}$ Specifically, in a context where the actual proportion of egoistic counterparts is $p_{0}$, Di Tella, et al., argue that a self-servingly biased decision maker "may form a biased belief [...] instead of correctly remembering a proportion of $p_{0}$ of low-type, the individual may try to convince herself that the proportion was actually $p>p_{0}$ " (p. 3437).
} 
consistent and, in doing so, provide important evidence on the nature of strategic selfdeception.

First, we show that a closer inspection of Di Tella, et al.'s, data reveals that their results, like ours, do not actually show any absolute cynicism or bias on the part of individuals with an incentive to act egoistically. In fact, the subjects in their experiment with the greater incentive to engage in strategic self-deception provide belief estimates very close to the actual frequency of egoistic behavior by their counterparts. In contrast, those subjects with a low incentive to engage in strategic cynicism exhibit the most bias, but in the direction of believing that their opponents will be less egoistic than they actually are. Thus, to the extent that an empirical bias exists in Di Tella, et al.'s, data, it seems not to be one of cynicism, but rather one of optimism and positivity that arises only among those with little ability to take from their opponent.

We next show that, theoretically, this positivity bias can be explained by a simple model that serves as a stylized representation of the games in both ours and Di Tella, et al.'s, experiments. In the model, Ann derives utility from her own and Bob's payoffs and this utility is increasing in Bob's kindness. When Ann has the opportunity to take from Bob, she has an incentive to reduce her belief regarding Bob's kindness; this diminishes the loss in utility she experiences by taking from him. However, in this setting individuals also have an incentive to form another kind of motivated belief - to convince themselves that the other player is kind and deserves any payoff she receives. The net result of these two opposing tendencies is an absolute bias in the direction of positivity, which is consistent with a general tendency for distorted beliefs to lie in the direction of positivity and optimism, rather than the opposite (Bénabou and Tirole, 2016). This simple theoretical analysis provides a basis for two phenomena we observe in our first experiment and in Di Tella, et al.'s, data. First, in absolute terms, biases about others' actions will lie in the direction of positivity rather than cynicism. ${ }^{4}$ Second, consistent with Di Tella, et al.'s, interpretation of their findings, the relative positivity of Ann's beliefs about Bob's behavior will be lower as Ann has a greater opportunity to take money from Bob. Thus, viewed jointly, these predictions suggest that, at least in many settings, strategic cynicism may be a relative rather than an absolute phenomenon.

The above analysis yields a straightforward interpretation for the absence of absolute strategic cynicism in our first experiment and the presence of relative strategic cynicism in

\footnotetext{
${ }^{4}$ This prediction also arises under the model that Di Tella, et al., use to motivate their experiment, though their analysis does not investigate this property.
} 
the study by Di Tella, et al. However, existing empirical support for the above two predictions involves comparisons across studies, in which changing populations or incidental factors may yield varying results. Therefore, in a third step, we test the two predictions in a novel experiment. We conduct a replication of Di Tella, et al.'s, study, but also elicit the beliefs of neutral observers regarding the behavior of subjects in the role of Bob. ${ }^{5}$

In this new experiment, we replicate Di Tella, et al.'s, main finding - a comparative static result that individuals with a greater opportunity to take from their counterparts hold less positive beliefs about these opponents. This replication itself is noteworthy, as we have a substantially larger sample size and find qualitatively similar findings in a different population, in Switzerland rather than Argentina, in a society that differs in general levels of corruption, trust and trustworthiness. However, we also once more document a lack of strategic cynicism in absolute terms. The beliefs of individuals in the role of Ann with a strong incentive to engage in strategic cynicism are no more cynical about Bob's behavior than either the empirical frequency of actual choices or the beliefs of neutral third parties without any incentive to adopt a negative view of Bob's likely actions.

Our results should not be interpreted as questioning Di Tella, et al.'s, findings. In fact, we provide a direct replication of their main result of relative strategic cynicism. However, we additionally provide clear evidence - across both of our studies and in Di Tella, et al.'s, original data - that there is no strategic cynicism in absolute terms. Instead, we find that strategic beliefs are positively biased. Our contribution thus expands our understanding of the psychological forces behind self-serving belief manipulation, by noting that strategic cynicism may compete with a tendency towards positivity in determining individuals' beliefs. Such a tendency towards positivity is consistent with overwhelming evidence of a general “positivity illusion" (Taylor and Brown, 1988) from psychological studies: people hold overoptimistic beliefs about future life events (Weinstein 1980, 1989), are too optimistic about the degree of personal control (Langer, 1975), hold too positive perceptions of themselves (Svenson, 1981; Quattrone and Tversky, 1984), engage in wishful thinking (Irwin, 1953), and hold beliefs that the world is just (Lerner, 1980). ${ }^{6}$ This positivity bias can also explain why, in contrast to our study, many other studies found strong evidence for

\footnotetext{
${ }^{5}$ Di Tella, et al., argue that one of their experimental treatments provides an estimate of unbiased beliefs. However, as we discuss in detail below (see footnote 17), there are a few reasons why these estimates are unlikely to correspond to the unbiased beliefs of subjects in their main experiment.

${ }^{6}$ In economics, Haisley and Weber (2010) document a tendency to believe that the impacts of one's choices on others are more positive than they actually are, while Andreoni and Sanchez (2014) find that subjects are too optimistic about other players' trust and trustworthiness compared to actual behavior.
} 
motivated reasoning (in non-strategic settings). We therefore contribute to a better understanding of the specific contexts, in which we should expect biased beliefs to arise. ${ }^{7}$

The next section provides a detailed description of our first study using the preemptive taking game. In Section 3, we discuss the study by Di Tella, et al., show that their findings do not provide evidence of strategic cynicism in absolute terms and present a stylized model that can provide an interpretation of behavior in both experiments. Section 4 presents our second experiment, intended to test this model more directly and reconcile the earlier results. Finally, Section 5 concludes.

\section{Study 1: An experimental test of strategic cynicism}

We first introduce the pre-emptive taking game, which allows us to test for absolute bias in strategic beliefs. Then, we discuss the experimental implementation of the game and present our results.

\subsection{The pre-emptive taking game}

There are two players, Ann and Bob. Both players start with an endowment of 10. They play a sequential game. In Stage 1, Ann decides how much to take from Bob's initial endowment. She can take any amount, $a \in\{0,2,4, \ldots, 10\}$. After Stage 1, Ann's wealth equals $10+a$, while Bob's equals $10-a$.

In Stage 2, after observing $a$, Bob decides how much to take from Ann's current endowment, $b$, once again in increments of two. The amount that Bob can take is constrained by Bob's remaining wealth. Specifically, in order to take $b$ units from Ann, Bob has to spend $0.5 \mathrm{~b}$ from his remaining wealth and cannot spend more than the amount he has at the beginning of Stage 2. Furthermore, Bob cannot take more than Ann's wealth at the beginning of Stage 2. Thus, Bob's ability to take is given by, $b \in\{0, \ldots, \bar{b}\}$, where $\bar{b}=\min (2(10-$ $a), 10+a)$. Hence, in the case in which Ann took everything in Stage 1 (i.e., $a=10$ ), Bob cannot take anything in Stage 2.

After Stage 2, the game concludes. The two players' payoffs are determined as follows:

$$
\pi_{A}=10+a-b
$$

\footnotetext{
${ }^{7}$ Other studies that demonstrate limits in the extent to which motivated reasoning and justifications facilitate egoistic behavior are van der Weele, Kulisa, Kosfeld and Friebel (2014) who find that people do not use "moral wiggle room" (see Dana, Weber and Kuang, 2007) in the context of reciprocity and Bartling and Özdemir (2017) who find that people do not employ the "replacement logic" ("if I don’t do it, someone else will") in contexts with a strong social norm.
} 


$$
\pi_{B}=10-a+b-0.5 b
$$

As an example, suppose Ann decides to take 6 in Stage 1 such that $a=6$. At the beginning of Stage 2, Ann has 16 and Bob has 4. In this case, in Stage 2, Bob can spend up to 4 to take up to 8 from Ann; doing so would leave both Ann and Bob with final payoffs of 8 . Under standard egoistic preferences, in the unique subgame-perfect Nash equilibrium to the game both Ann and Bob take as much as they can, i.e., $a=10$ and, consequently, $b=\bar{b}=0$.

The key feature in the pre-emptive taking game is that Bob's ability to take from Ann is limited by how much he has left at the end of Stage 1. Ann can thus protect herself from Bob's potentially egoistic behavior by taking all his tokens. Therefore, suppose Ann wants to obtain as high a payoff as possible, but also feels obligated to be fair to Bob in the case he does not intend to take from her. In such a case, Ann may justify taking by convincing herself that Bob intends to act greedily-i.e., by engaging in strategic cynicism. The critical measure of strategic cynicism in studying this game is thus Ann's beliefs about Bob's behavior. In particular, eliciting these beliefs and comparing them to neutral and objective standards - the actual amount of taking by Bob and neutral observers' beliefs about Bob's taking —allows us to test whether they exhibit a systematic bias toward negativity.

\subsection{Experimental design}

At the beginning of each session, participants are randomly assigned to one of three roles: Player A (Ann), Player B (Bob) and Player C (neutral observer). Subjects are informed of their own role. Next, all subjects receive the same set of instructions. The instructions describe all decisions made by Player A, Player B and the neutral observer in detail and subjects are provided with a detailed table showing all the possible combinations of payoffs resulting from the two strategic players' actions. ${ }^{8}$ After hearing the instructions read aloud, all participants answer questions about the decisions available to Players A and B and the consequences of these decisions.

For the pre-emptive taking game, Players $\mathrm{A}$ and $\mathrm{B}$ each start with an initial endowment of 10 chips, with each chip worth CHF $2(\approx \$ 2)$. In each pair, Player A selects how much to take from Player B $(a)$. Player B's choices are elicited using the strategy method-Player B selects an amount to take $\left(b_{a}\right)$ for every possible choice made by Player A. After both Player A and Player B have made their decisions, but before they learn about the payoffs, we elicit their beliefs concerning their counterpart's behavior. Player B guesses

\footnotetext{
${ }^{8}$ The instructions are available in the Appendix.
} 
which value of $a$ Player A selected $\left(\hat{a}^{B}\right)$. Player A guesses a value of $b$ for every possible value of $a$, or $\hat{b}_{a}^{A}$; at the end of the experiment one value of $a$ is randomly selected to count for Player A's guess. Each subject earns an additional CHF 4 if they accurately guess the choice made by their opponent. ${ }^{9}$

Individuals in the role of Player $\mathrm{C}$ are not matched with any pair and are not directly affected by the choices made by any specific Player A or B. Hence, they act as neutral participants, who have no incentive to bias their beliefs about other participants' actions. For our purposes, they provide a measure of unbiased beliefs about the actions of Player As and Bs. Specifically, each neutral observer guesses the choice of a randomly selected Player A $\left(\hat{a}^{C}\right)$ and the conditional choices of a randomly selected Player B $\left(\hat{b}_{a}^{C}\right)$. Similarly to the other participants, each Player C gains CHF 4 for correctly guessing the behavior of a Player A and CHF 4 for correctly guessing one randomly selected option for a Player B.

After making all choices, participants are informed about their payoffs. They then answer several socio-demographic questions before they are paid in private.

We conducted seven sessions with between 30 and 36 participants, resulting in a total of 240 participants, 80 in each role. ${ }^{10}$ All sessions took place at the Decision Sciences Lab (DeSciL) at the Federal Institute of Technology (ETH) in Zurich in 2015. Participants were recruited using hroot (Bock, Baetge and Nicklisch, 2014) from the joint subject pool of the University of Zurich and the ETH. The experiment was implemented using z-Tree (Fischbacher, 2007).

\subsection{Results}

On average, Player A took 8.0 tokens (std. dev. = 3.6) from Player B, with 50 of 80 , or 62.5 percent, taking the full amount, $a=10$. Figure A1 in the Appendix provides the full distribution of amounts taken.

Taking by Player A is related to beliefs about how much Player B will take. Figure 1 shows the average belief of Player A regarding how much Player B will take, in response to every possible action by Player A. The figure presents these mean beliefs separately for those who took less than 10 ("a $<10$ ") and those who took everything ("a $=10$ "). Those subjects in

\footnotetext{
${ }^{9}$ The amount of CHF 4 as an incentive for accurate guesses was the same for all sessions, except of the first session. In this session, the incentive for accurate guesses was CHF 2. We raised the incentive subsequently to provide subjects with more earnings opportunity. We find no differences in accuracy of guesses due to different incentives.

${ }^{10}$ We conducted two waves: the first four sessions were in Wave 1 while the remaining three sessions were in Wave 2. The second wave included elements intended to better ensure comprehension. We pool the data, as there is no difference in behavior between the two waves. The appendix provides instructions for both waves.
} 
the role of Player A who took everything hold more cynical beliefs about Player B. For instance, for the hypothetical case where Player A takes nothing $(a=0)$, those who actually took all 10 have mean beliefs that are much more cynical (8.16) than those who took less than 10 (4.2), and this difference is highly statistically significant $\left(\mathrm{t}_{78}=4.44, \mathrm{p}<0.001\right)$. Comparisons of mean beliefs for the cases in which Player A takes $a=2$ or $a=4$ similarly reveal differential cynicism between those who took 10 and those who took less (respectively, $\mathrm{t}_{78}=4.72, \mathrm{p}<0.001$ and $\mathrm{t}_{78}=2.85, \mathrm{p}<0.01$ ). This positive relationship between taking by Player A and negative beliefs about Player B's behavior is consistent with strategic cynicism but does not demonstrate it. Indeed, the more straightforward interpretation is that subjects in the role of Player A might simply be responding to their beliefs-taking more preemptively if they fear that B will also take more. ${ }^{11}$

\section{Figure 1: Player A beliefs about Player B's actions by Player A type}

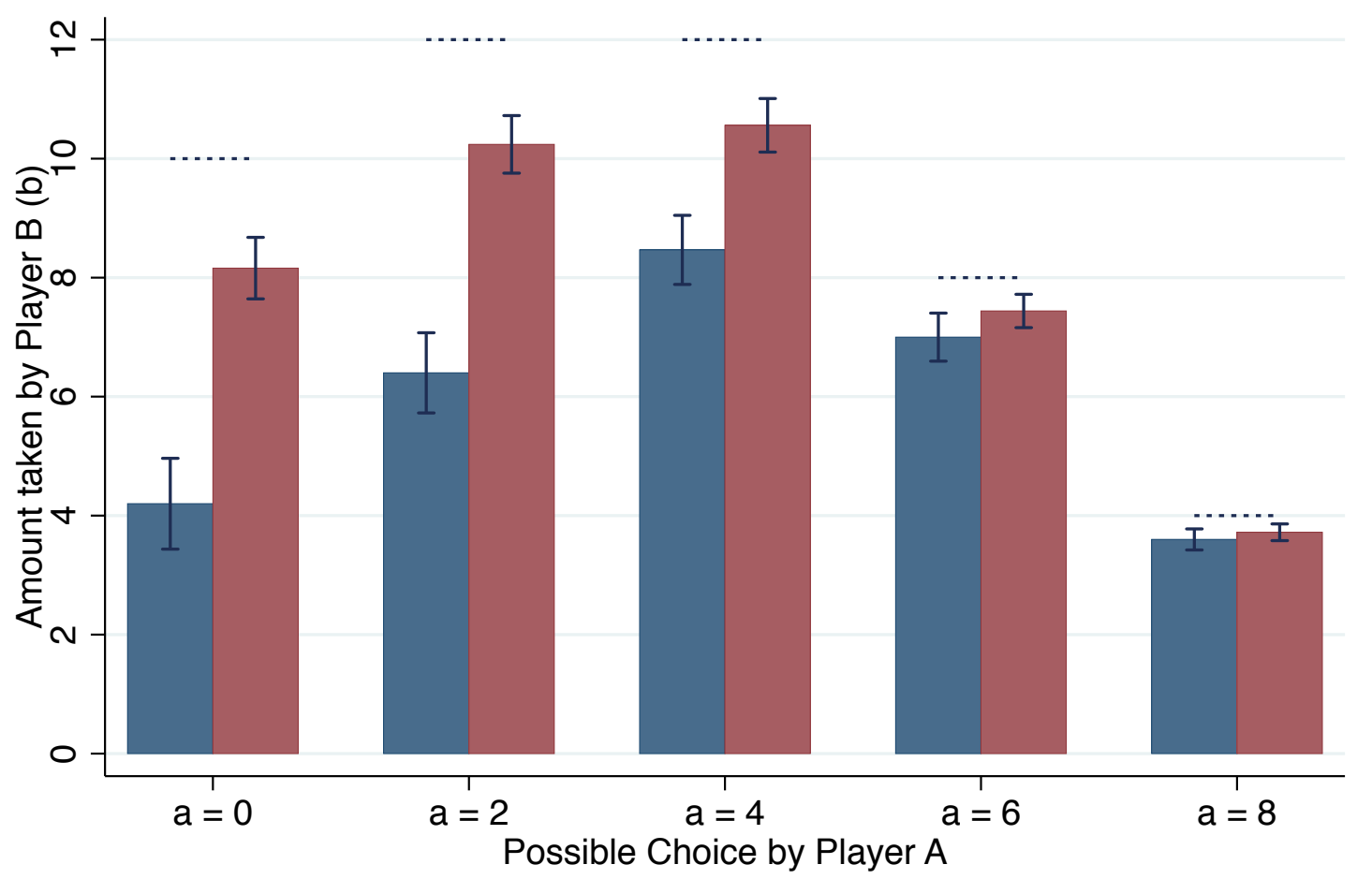

Guess by Player A $(a<10)$

Guess by Player A $(a=10)$

Note: The figure displays mean predictions by A of how much B will take, conditional on how much they took themselves. The category " $a<10$ " represents Player As who took less than 10 from Player $B$, while the category " $a=10$ " represents Player As who took the maximum possible from their counterparts. Dotted lines indicate the maximum possible amount $B$ could take. Bars indicate standard errors.

\footnotetext{
${ }^{11}$ This is in line with results in Fischbacher and Gächter (2010) who find, using a public good game, a positive relationship between participants' own contributions and their beliefs about others' contributions.
} 
To investigate strategic cynicism, our main focus, we next compare the beliefs of subjects in the role of Player A with two standards corresponding to unbiased beliefs. Strategic cynicism would imply that the beliefs of Player A about B's action predict more taking than the actual amount taken by Player $\mathrm{B}\left(\hat{b}_{a}^{A}>b_{a}\right)$ and than the corresponding predictions by Player $\mathrm{C}\left(\hat{b}_{a}^{A}>\hat{b}_{a}^{C}\right)$. Figure 2 shows, for each possible action by Player A, how much Player B actually took on average and the corresponding mean beliefs by subjects in the roles of Player A and Player C.

Looking first at the actual behavior of subjects in the role of Player B, we observe that the amount they take depends on Player A's choice. For instance, when Player A takes nothing, then the average amount taken, $b_{a=0}$, equals 5.63, even though Player B could take anywhere between 0 and 10 tokens. As Player A takes more, Player B also seizes a larger proportion of the available tokens. For instance, when Player A takes either 2 or 4 tokens, meaning that Player B can take anywhere between 0 and 12 , then $b_{a=2}=8.53$ and $b_{a=4}=$ 9.65, on average. Finally, when A takes most of B's endowment, B takes, on average, very close to the maximum possible amounts $\left(b_{a=6}=7.53\right.$ and $\left.b_{a=8}=3.90\right){ }^{12}$

\section{Figure 2: Actual conditional taking by $B$ and corresponding predictions by $A$ and $C$}

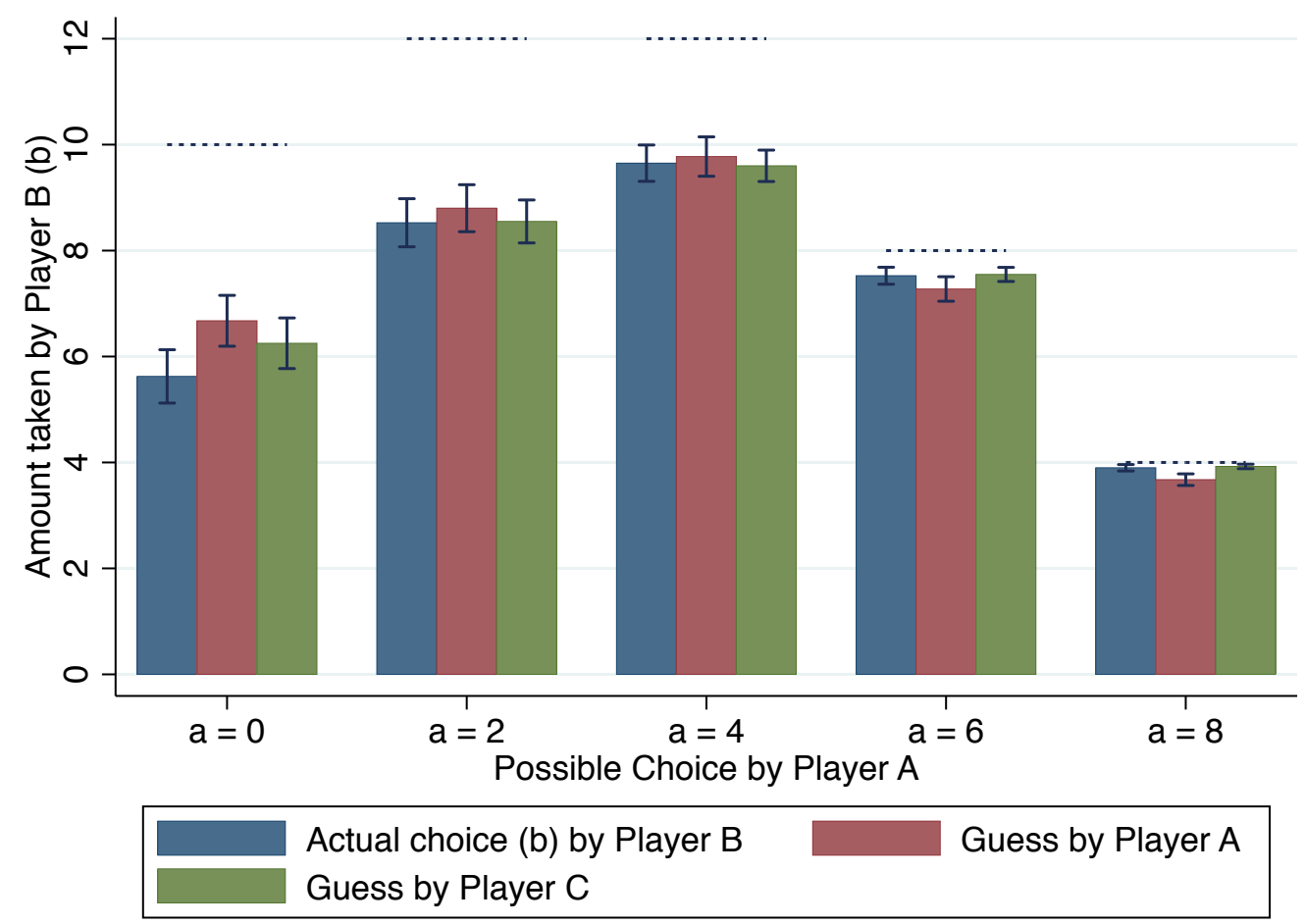

Note: Actual choices by Player Bs and predicted choices about Player B's behavior by Player As and the neutral observers (Player Cs), respectively. Dotted lines indicate the maximum possible amount B could take. Bars indicate standard errors.

\footnotetext{
${ }^{12}$ Figure A2 in the Appendix provides the distributions of taking by B, for every possible amount taken by A.
} 
Perhaps the most striking finding in Figure 2 is how little evidence we find of strategic cynicism. For every possible amount taken by Player A, the beliefs of Player A and Player C regarding Player B's choice are very close to each other and to the actual behavior of Player B. Table 1 presents statistical tests of the relationships between Player A's beliefs and the actual choices by Player B and the beliefs of Player C. There are no statistically significant differences between the beliefs of Player A $\left(\hat{b}_{a}^{A}\right)$ and the actual behavior of Player $\mathrm{B}\left(b_{a}\right)$ or the beliefs of Player $\mathrm{C}\left(\hat{b}_{a}^{C}\right)$ for any amount taken by A between 0 and 6 . In the case where A takes 8 , the differences are at least marginally statistically significant, but in these comparisons A underestimates B's taking, both relative to the actual amount and to the beliefs provided by $\mathrm{C}^{13}$

Table 1. Statistical tests of strategic cynicism

\begin{tabular}{c|c|cc|cc} 
& $\begin{array}{c}\text { Mean taking } \\
\text { by B }\left(b_{a}\right)\end{array}$ & $\begin{array}{c}\text { Mean guess } \\
\text { by A }\left(\hat{b}_{a}^{A}\right)\end{array}$ & $\begin{array}{c}\text { Mean guess } \\
\text { by C }\left(\hat{b}_{a}^{C}\right)\end{array}$ & $\hat{b}_{a}^{A}$ vs. $b_{a}$ & $\hat{b}_{a}^{A}$ vs. $\hat{b}_{a}^{C}$ \\
\hline \multirow{3}{*}{$a=0$} & 5.625 & 6.675 & 6.250 & $t_{158}=1.510$ & $t_{158}=0.678$ \\
& $(0.503)$ & $(0.480)$ & $(0.478)$ & $\mathrm{p}=0.133$ & $\mathrm{p}=0.531$ \\
$a=2$ & 8.525 & 8.800 & 8.550 & $t_{158}=0.433$ & $t_{158}=0.416$ \\
& $(0.454)$ & $(0.444)$ & $(0.406)$ & $\mathrm{p}=0.666$ & $\mathrm{p}=0.678$ \\
$a=4$ & 9.650 & 9.775 & 9.600 & $t_{158}=0.247$ & $t_{158}=0.368$ \\
& $(0.343)$ & $(0.371)$ & $(0.296)$ & $\mathrm{p}=0.805$ & $\mathrm{p}=0.713$ \\
$a=6$ & 7.525 & 7.275 & 7.550 & $t_{158}=0.889$ & $t_{158}=1.031$ \\
& $(0.160)$ & $(0.231)$ & $(0.133)$ & $\mathrm{p}=0.375$ & $\mathrm{p}=0.304$ \\
$a=8$ & 3.900 & 3.675 & 3.925 & $t_{158}=1.800$ & $t_{158}=2.130$ \\
& $(0.061)$ & $(0.109)$ & $(0.043)$ & $\mathrm{p}=0.074$ & $\mathrm{p}=0.035$
\end{tabular}

Standard errors in parentheses

\subsection{Discussion}

To summarize, we find a positive relationship between cynicism about one's opponent and the number of tokens taken by subjects in the role of Player A. That is, subjects who hold cynical beliefs about their opponents take more from them. However, our data

\footnotetext{
${ }^{13}$ The statistical tests in Table 1 are t-tests. Non-parametric Wilcoxon rank-sum tests yield very similar results; all p-values for $a=0$ through $a=6$ are greater than 0.188 and the p-values for $a=8$ are $0.071\left(\hat{b}_{a}^{A}\right.$ vs. $\left.b_{a}\right)$ and $0.066\left(\hat{b}_{a}^{A}\right.$ vs. $\left.\hat{b}_{a}^{C}\right)$.
} 
reveal very little evidence of self-serving belief manipulation by subjects in the role of Player A, neither relative to objective behavioral standards nor to the beliefs of unbiased observers. ${ }^{14}$

While our results rule out significant levels of strategic cynicism in our data, they stand in contrast to Di Tella, et al. (2015), who conclude from their experimental evidence that people engage in self-serving manipulation of their strategic beliefs. We next describe this evidence and attempt to reconcile our seemingly conflicting results.

\section{Reconciling our results with Di Tella, et al. (2015)}

Di Tella, et al. (2015), study strategic cynicism using a "corruption game.” In contrast with our findings, they conclude that decision makers bias their beliefs about a counterpart's egoism in response to incentives. In this section, we first describe their study and findings in detail and then offer evidence that our two sets of results are similar in that neither yields evidence of an absolute bias in individuals' beliefs.

\subsection{Di Tella, et al. 's, corruption game}

The study by Di Tella, et al., is based on the idea that a greater opportunity to act egoistically at the expense of a counterpart creates stronger incentives to engage in strategic cynicism. Hence, their main prediction is that those with greater opportunities to act egoistically should end up with a more pessimistic belief about the counterpart's kindness.

Di Tella, et al., test this comparative-static prediction in a "corruption game." 15 In the game, an "Allocator" and a "Seller" each start with 10 tokens. The Allocator decides how to redistribute the combined 20 tokens between herself and the Seller. Simultaneously, the Seller sets the "price" at which all the tokens are sold to the experimenter. He can either choose a price of 1.50 Argentine pesos $(\$)$ or a price of $\$ 0.50$. If the Seller chooses the latter, he additionally receives a fixed side payment of $\$ 5$. Setting a lower price while taking the side payment is labeled as a "corrupt" act by the Seller, akin to accepting a bribe.

In addition to deciding upon the distribution of tokens, the Allocator also provides beliefs $(\hat{p})$ about the likelihood that her paired Seller takes the corrupt action and about the share of Sellers in the experimental session that does so. The Allocator receives $\$ 5$ for each

\footnotetext{
${ }^{14}$ The beliefs of Player Bs and Cs about A's actions are similarly unbiased (see Figure A3 in the Appendix). Recall that the mean amount taken by $\mathrm{A}$ is 8.0 (std. dev. = 0.358). Player Bs and C report mean beliefs that are slightly higher $\left(\hat{a}^{B}=8.35(0.280), \hat{a}^{C}=8.53(0.258)\right)$ but these differences are not statistically significant-all comparisons using t-tests or rank-sum tests yield $\mathrm{p}>0.23$.

${ }^{15} \mathrm{Di}$ Tella, et al., present the results of two different corruption games. We describe the game used in their preferred study, the modified corruption game. The formal games only differ in their payoffs.
} 
correct guess. These beliefs - the key measure in Di Tella, et al.'s, experiment - provide estimates of the (possibly biased) beliefs that the Allocator has about Sellers' behavior.

Di Tella, et al., identify strategic cynicism with a treatment distinction that varies constraints on Allocators" ability to redistribute tokens. In the "Able $=2$ " treatment, the Allocator can move up to two tokens; that is, she can implement one of the following five payoff distributions: $(8,12),(9,11),(10,10),(11,9),(12,8)$. In the "Able $=8$ " treatment, the Allocator can move up to eight tokens, meaning that the allocations, $(2,18),(3,17), \ldots,(17$, $3),(18,2)$, are all possible. Hence, the treatment manipulation endows some Allocators with the ability to appropriate up to eight of the Sellers' tokens and other Allocators with the ability to appropriate only up to two tokens. Importantly, however, a Seller is not informed of whether his paired Allocator can move two or eight tokens, meaning that Allocators, who are aware of Sellers' ignorance regarding the treatment, should form beliefs about Sellers' behavior that are independent of the treatment. ${ }^{16}$ Instead, Di Tella, et al., argue that the treatment manipulation affects the value of engaging in self-deception, as "allocators who can take more tokens from the seller (i.e., Able $=8$ instead of Able $=2$ ) have more incentives to convince themselves that the seller is unkind" (p. 3417), that is, $\hat{p}_{\text {Able }=2}<\hat{p}_{\text {Able }=8}$.

Di Tella, et al.'s, experimental results are consistent with this prediction. Individuals who have a greater ability to take from their counterpart take more and, more importantly, reveal more pessimistic beliefs about their counterpart's corruption. This appears to contrast with the findings of our first experiment, which reveal no strategic cynicism.

\subsection{Relative or absolute cynicism?}

To reconcile the apparent discrepancy, first note that our first study sought to identify strategic cynicism through the observation that individuals bias their beliefs about a counterpart's actions relative to the objective reality or to the beliefs of unbiased observers. Specifically, suppose there is some measure of an opponent's (expected) kindness, $d$-where unkindness, or $1-d$, corresponds to $b$ in the pre-emptive taking game or $p$ in the corruption game. If $\hat{d}$ represents a decision maker's beliefs about the opponent's kindness, then our strategic cynicism hypothesis is that a decision maker who can take from the opponent will perceive the opponent to be less kind than he actually is, or $\hat{d}<d$. In the case of Di Tella et al.'s experiment, for instance, this corresponds to the belief that $p$ is higher than it actually is

\footnotetext{
${ }^{16}$ This design leaves open the possibility that Allocators' differential beliefs are the result of the "curse of knowledge" or information projection (Camerer, Loewenstein \& Weber, 1989; Madarasz, 2012), whereby decision makers find it difficult to ignore their private information when guessing others' beliefs.
} 
(see footnote 3 ). Instead, our first study finds that $\hat{d} \approx d$, both when we measure $d$ using empirical behavior as the benchmark or the beliefs of unbiased observers.

Di Tella, et al.'s, experiment and findings, however, demonstrate something different. Specifically, they test whether a decision maker with a greater incentive to take from the opponent will perceive the opponent to be less kind than will a decision maker with a reduced incentive to take. That is, if we let $\hat{d}^{\prime}$ represent the beliefs of a decision maker with a restricted taking opportunity - as with Allocators in the Able $=2$ condition - then Di Tella, et al.'s, findings demonstrate that those who are constrained to take less adopt relatively more positive beliefs of their opponent's kindness, $\hat{d}^{\prime}>\hat{d}$. Indeed, this relative comparison is also the basis of the main theoretical proposition with which they motivate their study.

The discrepancy in our findings is straightforward to reconcile if one recognizes that a relative bias and an absolute bias may not coincide. That is, if subjects in Di Tella, et al.'s, study do not exhibit an absolute bias in the direction predicted by strategic cynicism - that is, if $\hat{d}^{\prime}>\hat{d} \geq d$ - then the two sets of results are entirely consistent.

Di Tella, et al., do not explicitly collect a measure of the unbiased beliefs of neutral observers. ${ }^{17}$ However, we can compare Allocators' guesses to the empirical frequency of Sellers' corruption. In Di Tella, et al.'s, first experiment, the actual proportion of Sellers who chose the corrupt option was 75 percent. Using the more precise measure of Allocators' estimates, and the only one that was incentivized, we see that those Allocators with a greater ability to take money $(\mathrm{Able}=8)$ provided estimates ( 69 percent) that were fairly close to the empirical benchmark and, if anything, underestimated Sellers' corruption. On the other hand, the Allocators who had a reduced ability to take $($ Able $=2)$ provided estimates (49 percent) that were much farther from the true percentage. Similarly, in the second experiment, the frequency of corrupt behavior by Sellers was 66 percent. The estimates provided by those who could take more $($ Able $=8)$ tended to exhibit very little bias (64 percent), while the estimates from those who could take less $($ Able $=2)$ were again biased in the direction of believing too little corruption on the part of Sellers (48 percent).

\footnotetext{
${ }^{17}$ Di Tella, et al., argue that an additional treatment in which Allocators are forced to take a pre-specified amount from the Seller, and in which the mean estimate is 56 percent, provides "a rough estimate of what the average [estimate] would have been in the Modified Game if Allocators had not incurred in self-deception." However, these are not the estimates of unbiased observers, but of individuals interacting with the counterpart. In the simple model we develop below, such individuals have an incentive to view the opponent kindly. In addition, eliminating the Allocator's choice altogether substantively changes the game-e.g., Sellers now confront a unilateral decision problem rather than a strategic game. Therefore, the beliefs of the Allocators in this game can only very cautiously be interpreted as corresponding to Allocators' (unbiased) beliefs in the corruption game. Finally, there are very few observations in this treatment (15 if one uses the same rules for excluding subjects as in other treatments - see footnote 25 in Di Tella, et al., 2015).
} 
Our observations — based on our data and that of Di Tella, et al.—suggest that, to the extent a bias exists, it is one of positivity and the belief that opponents will be kinder than they actually are. While Di Tella's, et al.'s, evidence points to greater relative strategic cynicism on the part of those with more opportunity to take-i.e., $\hat{d}^{\prime}>\hat{d}$ - there is very little evidence of strategic cynicism on an absolute level—instead, it appears that $\hat{d}^{\prime}>\hat{d} \geq d$. We next demonstrate how a very simple model can provide an interpretation for these patterns.

\subsection{A simple model of strategic cynicism}

In this section, we introduce a simple model that can account for the above patterns. We do not attempt to derive a general model of belief formation or self-deception. Instead, we study a simple and highly stylized representation of a decision in a non-strategic context, where an individual decides on a wealth allocation between herself and a counterpart and cares about this counterpart's perceived kindness or unkindness. It shares many features with the model used by Di Tella, et al., to motivate their experiment —indeed, the main predictions of our analysis can also be generated using their model. ${ }^{18} \mathrm{We}$ acknowledge that alternative modeling approaches may yield different predictions; however, we present this model merely as an example of the kind of model that can provide an interpretation for the above patterns we observe in our first experiment and in the study by Di Tella, et al., and that we can further test in a novel experiment.

Ann decides how to split an amount of money, normalized to 1, with Bob. Ann can take at most $K \in(0,1]$ for herself. Bob has one of two possible types, which represent the extent to which he is a "good" or "bad" person and is therefore perceived by Ann to deserve greater or less wealth: with probability, $p \in(0,1)$, Bob is a low-deservingness type $(L)$ and with probability, $1-p$, Bob is a high-deservingness type $(H)$. Ann is altruistic, but she cares less for the welfare of the low type. Specifically, she puts weight $d_{L}>0$ on the low type's payoff and weight $d_{H}>d_{L}$ on the payoff of the high type. To incorporate motivated reasoning and self-deception, Ann can bias her belief, $\hat{p}$, about the share of low types. However, this incurs a psychological cost, $C(|p-\hat{p}|) \cdot{ }^{19}$ In addition, as in our experiments and those of Di Tella, et al., Ann is incentivized to hold unbiased beliefs by a monetary

\footnotetext{
${ }^{18}$ Our model differs in important points (e.g., we formally incorporate the restriction $K$ ). Di Tella, et al., discuss a result related to Proposition 2, but no result related to Proposition 1.

${ }^{19}$ We capture motivated reasoning similarly to Rabin (1994) and Konow (2000). For other examples of models with motivated beliefs, see Bénabou and Tirole (2006, 2011), Bénabou (2013), Brunnermeier and Parker (2008), and Bodner and Prelec (2002, 2003).
} 
payoff function $P(|p-\hat{p}|)$. Since Ann does not know Bob's actual type, the weight she assigns to Bob's payoff equals its expected value, $E_{\hat{p}}(d)=\hat{p} d_{L}+(1-\hat{p}) d_{H}$.

Ann's behavior is then captured by the following maximization problem:

$$
\max _{x \in[0, K], \hat{p} \in[0,1]} \mathrm{U}(x, \hat{p})=v(x)+E_{\hat{p}}(d) v(1-x)+P(|p-\hat{p}|)-C(|p-\hat{p}|),
$$

where $x$ represents the share that Ann takes for herself. The function $v:[0,1] \rightarrow \mathbb{R}_{>0}$ is a $C^{1}$ function with $v^{\prime}>0, P:[0,1] \rightarrow \mathbb{R}_{\geq 0}$ is a $C^{2}$ function with $P^{\prime}<0$ and $P^{\prime \prime} \leq 0$, and $C:[0,1] \rightarrow \mathbb{R}_{\geq 0}$ is a $C^{2}$ function with $C^{\prime}>0$ and $C^{\prime \prime}>0 .{ }^{20}$

This model generates two predictions that are consistent with the above empirical observations (all proofs are in Appendix B). First, Proposition 1 shows that Ann is, if anything, too positive regarding Bob's deservingness.

Proposition 1: For any $(x, \hat{p})$ in $\operatorname{argmax}_{x \in[0, K], \hat{p} \in[0,1]} \mathrm{U}(x, \hat{p}), \hat{p} \leq p$.

This result is due to the fact that her utility increases in Bob's deservingness; that is, Ann prefers to think of Bob as being the more deserving type. Thus, in absolute terms, Ann's bias will always be to think of Bob as kinder than he actually is.

Proposition 2 states that, in relative terms, Ann will be more cynical—or less positive- when she has the opportunity to take more from Bob.

Proposition 2: Take $K, K^{\prime}$ in $(0,1]$ with $K^{\prime}<K$ and suppose that there is a unique solution to (1) for both $K$ and $K^{\prime}$, then $\hat{p}^{\prime} \leq \hat{p}$.

Thus, Proposition 2 provides a basis for the differences in relative beliefs between subjects who could take varying amounts from their opponent in Di Tella, et al.'s, experiment. In summary, this model predicts a (motivated) bias in belief formation that provides a basis for the absence of absolute levels of cynicism: as Ann shares a positive amount with Bob, she likes to think of him as a deserving type and this motivation is stronger as she is constrained to take less money from him.

Next, we illustrate the choice problem for a neutral observer with no stake in the outcome of game. This individual reports his beliefs, $\hat{p}^{N}$, about the deservingness of a random person in the role of Bob and faces incentives for accuracy: he receives a payoff

\footnotetext{
${ }^{20}$ Note that there exists a solution to $(1)$ as $U(x, \hat{p})$ is continuous and the feasible set is compact.
} 
$P\left(\left|p-\hat{p}^{N}\right|\right)$. The observer can also adopt biased beliefs about $p$, but faces the cost, $C\left(\left|p-\hat{p}^{N}\right|\right)$, for doing so. The observer thus solves the following maximization problem:

$$
\max _{\hat{p}^{N} \in[0,1]} U\left(\hat{p}^{N}\right)=P\left(\left|p-\hat{p}^{N}\right|\right)-C\left(\left|p-\hat{p}^{N}\right|\right)
$$

where again $C^{\prime}>0$ and $P^{\prime}<0$. The observer maximizes his utility by having accurate beliefs:

Proposition 3: $\hat{p}^{N}=p$ is the unique solution to $\max _{\hat{p}^{N} \in[0,1]} U\left(\hat{p}^{N}\right)$.

Therefore, neutral observers report beliefs that correspond to the unbiased beliefs $p .^{21}$

Note that this simple model can account for the pattern observed in the above laboratory results. Our results in Study 1 are consistent with Propositions 2 and 3: $\hat{p} \leq p=$ $\hat{p}^{N}$. In the case of Di Tella, et al.'s, experiment, if we allow Able $=2$ to correspond to $K^{\prime}$ and Able $=8$ to correspond to $K$, the patterns in the data are consistent with both Propositions 1 and $2: \hat{p}^{\prime} \leq \hat{p} \leq p$. We next test these predictions jointly-specifically, that $\hat{p}^{\prime} \leq \hat{p} \leq \hat{p}^{N}=$ $p$-in a novel experiment.

\section{Study 2: Jointly testing absolute and relative strategic cynicism}

As we state above, the data from our first experiment and that of Di Tella, et al., provide, separately, support for all three of the above propositions. However, since we developed the model as a way to account for these observations, this is not particularly surprising. We next report a novel study that jointly tests all three predictions. The new experiment replicates Di Tella, et al.'s, experiment and further elicits the beliefs of neutral observers.

\subsection{Experimental design}

We began with a replication of Di Tella, et al.'s, corruption game, conducted in Switzerland. We used their instructions and replaced the monetary payoff of 1 Argentine peso with 1.20 Swiss Francs (CHF). ${ }^{22}$ This meant, for instance, that the payment for each correct guess by an Allocator was $C H F$ 6. In addition, we paid a participation fee of $C H F$

\footnotetext{
${ }^{21}$ See Konow (2000) for a very similar result, in the case of "Benevolent Dictators."

${ }^{22}$ Note that we substantially increased real incentives; in 2016, CHF 1 corresponded to 7.48 Argentine pesos (PPP adjusted; OECD, 2018).
} 
$15 .^{23}$ We made two further substantive changes to bring their classroom experiment into a laboratory setting. First, while their experiment was fully paper based, we implemented it via computers, using the z-Tree program (Fischbacher, 2007). Second, we used a slightly different procedure to guarantee participants' anonymity. ${ }^{24} \mathrm{We}$ conducted nine sessions, each with between 22 and 24 participants, resulting in a total of 212 participants (106 Allocators and 106 Sellers).

We also conducted an additional variant of the experiment - which we refer to as the "neutral" treatment - to elicit the unbiased beliefs of neutral observers. In these sessions, participants received "instructions provided to a participant in a previous experiment." Specifically, each participant saw either the instructions given to an Able $=2$ or an Able $=8$ Allocator, determined at random. Since the Allocators' instructions include the instructions given to Sellers, participants also read the Sellers' instructions and had knowledge of the entire game. We made explicit to participants that, first, these were not their instructions and that, second, at the end of the experiment they could earn money by providing accurate guesses about something that happened in the previous experiment. Therefore, participants had no incentives to engage in self-deception, but still had incentives to closely attend to the instructions and understand the corruption game.

After reading the instructions, participants in the neutral treatment first had to answer the same comprehension questions as in the design of Di Tella, et al., and in our replication, to make sure that they understood the game. Subsequently, they made two guesses identical to those made by Allocators in Di Tella, et al.'s, design and in our replication: they guessed the choice made by a randomly chosen Seller in the previous experiment and they guessed what percentage of Sellers in a previous session chose the corrupt option. As in the replication, they received $C H F 6$ for correct guesses, as well as a $C H F 15$ participation fee. We conducted two such neutral sessions, with a total of 55 participants.

All sessions took place at the Decision Sciences Laboratory at the Federal Institute of Technology (ETH) in Zurich, in 2016. Participants were recruited using hroot (Bock, Baetge

\footnotetext{
${ }^{23}$ Our first session paid only a participation fee of CHF 10 . We adjusted this payment upward to reflect the longer duration of the study than we originally expected.

${ }^{24}$ At the beginning of each session, one participant was randomly selected to be the "monitor." The remaining participants each received a random ID number hidden in an envelope, so that the experimenter could not match the ID to the participant. Subjects entered their ID numbers in their respective computer terminals. At the end of the study, we placed the amount of money earned by each participant in an envelope labeled only with the anonymous ID number and placed all envelopes on a table that participants passed on their way out of the laboratory. The monitor, who did not know the amount contained in any of the envelopes, controlled that each participant took only the correct envelope.
} 
and Nicklisch, 2014) from the joint subject pool of the University of Zurich and the ETH. All instructions for the replication and the neutral treatment are in the Appendix.

\begin{tabular}{|c|c|c|c|c|c|c|}
\hline & \multicolumn{3}{|c|}{ Modified Game (Di Tella, et al.) } & \multicolumn{3}{|c|}{ Replication } \\
\hline & Able $=2$ & Able $=8$ & p-value & Able $=2$ & Able $=8$ & $p$-value \\
\hline $\begin{array}{l}\text { Tokens } \\
\text { Taken }\end{array}$ & $\begin{array}{c}1.35 \\
(0.16)\end{array}$ & $\begin{array}{c}6.59 \\
(0.33)\end{array}$ & $<0.01$ & $\begin{array}{c}0.98 \\
(0.14)\end{array}$ & $\begin{array}{c}4.79 \\
(0.44)\end{array}$ & $<0.01$ \\
\hline Is Corrupt & $\begin{array}{c}0.48 \\
(0.09)\end{array}$ & $\begin{array}{c}0.85 \\
(0.06)\end{array}$ & $<0.01$ & $\begin{array}{c}0.19 \\
(0.05)\end{array}$ & $\begin{array}{c}0.49 \\
(0.07)\end{array}$ & $<0.01$ \\
\hline$\%$-Corrupt & $\begin{array}{c}0.48 \\
(0.04)\end{array}$ & $\begin{array}{c}0.64 \\
(0.03)\end{array}$ & $<0.01$ & $\begin{array}{c}0.33 \\
(0.04)\end{array}$ & $\begin{array}{c}0.47 \\
(0.04)\end{array}$ & $<0.01$ \\
\hline $\mathrm{N}$ & 31 & 34 & & 53 & 53 & \\
\hline
\end{tabular}

Notes: Standard errors in parentheses. P-value: $t$-test of the null hypothesis that the means under Able $=2$ and $\mathrm{Able}=8$ are equal.

\subsection{Results}

Table 2 compares the behavior and guesses of Allocators in Di Tella, et al.'s, experiment and in our replication. ${ }^{25}$ The mean tokens taken (Tokens Taken) by the Allocator is slightly lower in our replication. More importantly, the share of Allocators who think that their paired Seller chooses the "corrupt" side payment (Is Corrupt) differs significantly between the $A b l e=2$ and $A b l e=8$ treatment groups in both the original experiment and our replication. The same holds for the average stated belief of Allocators regarding the share of Sellers who choose the side payment (\%-Corrupt). Thus, despite the differences between the two studies - e.g., lab vs. field, Switzerland vs. Argentina—we replicate Di Tella, et al.'s, findings of relative strategic cynicism $\left(\hat{p}^{\prime} \leq \hat{p}\right){ }^{26}$

\footnotetext{
${ }^{25}$ Following Di Tella, et al., we conduct randomization tests with respect to demographic measures (gender, age and socioeconomic class). We find no significant differences between the Able $=2$, Able $=8$ and Neutral treatments.

${ }^{26}$ The statistical tests in Table 2 are t-tests. Non-parametric Wilcoxon rank-sum tests yield very similar results; p-values for Tokens Taken, Is Corrupt and \%-Corrupt are smaller than 0.01 .
} 
Table 3. Allocator and neutral observer beliefs

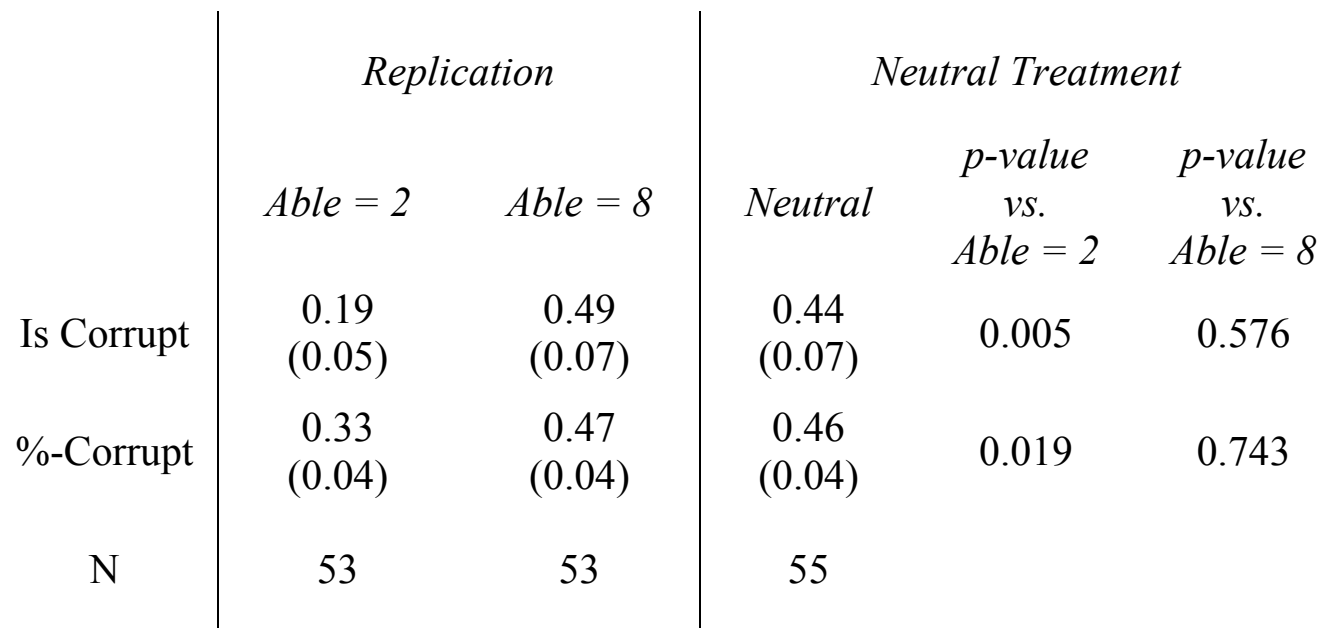

Notes: Standard errors in parentheses. P-value: t-test of the null hypothesis that the means under neutral and the corresponding replication $(\mathrm{Able}=2$ or Able $=8)$ mean are equal.

We next compare the beliefs provided by Allocators with those of neutral observers, to see whether $\hat{p}^{\prime} \leq \hat{p} \leq \hat{p}^{N}$ holds in our new study. Table 3 compares the estimates of unbiased beliefs we obtained in our neutral treatment with the estimates provided by both Able $=2$ and Able $=8$ Allocators in our replication. The final two columns report statistical tests of the differences between neutral observers' beliefs and those of the two types of Allocators. The neutral and unbiased estimate is 44 percent for Is Corrupt and 46 percent for $\%$-Corrupt. ${ }^{27}$ Both of these are close to - and statistically indistinguishable from-the beliefs provided by Allocators with the high opportunity to take (Able $=8)$, again suggesting that these allocators exhibit no bias (i.e., $\hat{p}=\hat{p}^{N}$ ). Moreover, the estimates of 44 and 46 percent are very close to the actual frequency of corrupt choices by Sellers (42 percent). Thus, similarly to our first experiment, neutral observers provide fairly accurate estimates of behavior. In contrast, the mean beliefs provided by Allocators in the Able $=2$ treatment are considerably more positive than the beliefs provided by neutral observers and these differences are statistically significant. ${ }^{28}$

The results of this study provide support for our interpretation of a key distinction between relative versus absolute strategic cynicism in our study and in the one of Di Tella, et al., and for the theoretical model we used to account for these observations. Comparing the

\footnotetext{
${ }^{27}$ There is no significant difference between the beliefs of neutral subjects who received the instructions of an Able $=2$ Allocator and those who received instructions of an Able $=8$ Allocator.

${ }^{28}$ Non-parametric Wilcoxon rank-sum tests yield very similar results; p-values for Is Corrupt are 0.006 for the comparison between the neutral and the Able $=2$ Treatment and 0.574 for the comparison between the neutral and the Able $=8$ Treatment; $p$-values for $\%$-Corrupt are 0.019 for the comparison between the neutral and the Able $=2$ Treatment and 0.835 for the comparison between the neutral and the Able $=8$ Treatment.
} 
behavior of Allocators with a high and low taking opportunity, we observe that the former hold relatively more cynical beliefs-i.e., that $\hat{p}^{\prime} \leq \hat{p}$, as in Proposition 2 . We also observe that, in absolute terms, the estimates provided by Allocators do not exhibit a tendency toward cynicism, relative to the unbiased estimates of neutral observers-i.e., $\hat{p}^{\prime} \leq \hat{p} \leq \hat{p}^{N}$, as in Propositions 1 and 3.

\section{Conclusion}

This paper studies whether the tendency to manipulate one's beliefs self-servingly extends to strategic cynicism, whereby an individual views her opponents' likely actions negatively when doing so can justify acting in a self-interested manner. We begin with a laboratory experiment that compares the beliefs of strategic players motivated to engage in strategic cynicism with the beliefs of neutral observers not incentivized to engage in any belief manipulation. We find no evidence that strategic actors manipulate their beliefs regarding opponents' behavior, thus seemingly contradicting the hypothesis of strategic cynicism, at least in absolute terms.

We then attempt to reconcile this observation with the results from Di Tella, et al. (2015), who find evidence of strategic belief manipulation, whereby subjects with greater opportunity to take money from another person are more cynical about the counterpart's likely behavior. This provides evidence of relative strategic cynicism, meaning that individuals become comparatively more cynical about their opponents when doing so justifies more self-interested behavior. However, Di Tella, et al.'s, data reveal very little evidence of strategic cynicism in absolute terms. Thus, one possible interpretation of the apparent discrepancy is that individuals exhibit relatively more pessimistic beliefs regarding the behavior of their counterparts when they stand to gain more from doing so, but that, in absolute terms, their beliefs will tend toward positivity rather than cynicism.

We show that this interpretation is consistent with a simple model-similar to the one that Di Tella, et al., use to motivate their study - in which individuals enjoy giving more if they believe that the beneficiaries are nicer. If we allow individuals to manipulate their beliefs with some cost for doing so, then the model can explain both of the above patterns. People benefit from thinking that they are acting toward kind others, but will believe these others to be less kind when greater cynicism lowers the costs of acting self-interestedly. Admittedly, this model is not general, but it provides a useful framework for reconciling the results of the two studies. 
To investigate this interpretation, we conducted a novel experimental test. Specifically, we first replicated Di Tella, et al.'s, experiment and then extended it to obtain new measures of unbiased beliefs from neutral observers. Our replication confirms Di Tella, et al.'s, observation of relative strategic cynicism. Nevertheless, we also find that any absolute bias in beliefs seems to lie in the direction of too much positivity, rather than cynicism, about counterparts' behavior, especially by those with a limited opportunity to act self-interestedly.

We thus find no evidence - across many comparisons - that decision makers justify treating another person unfairly by self-servingly adopting the belief that the counterpart herself intends to act more egoistically than is actually the case. Instead, in terms of an absolute level of bias, we find evidence for another form of motivated belief; namely, in the kinds of interactions we study here, individuals seem motivated to convince themselves of the deservingness of the counterpart, and end up with beliefs that are often too positive. The finding that people are too positive about other players' kindness supports a general tendency for distorted beliefs to lie in the direction of positivity and optimism rather than the opposite. In fact, a broad view of the literature suggests that there is little evidence that people systematically bias their beliefs in a negative direction. While it is certainly unreasonable to rule out the possibility that there are contexts in which people may also engage in such cynical self-deception - and that, in absolute terms, this may even occur in strategic settings - our analysis suggests that such a tendency is limited, at least in some contexts.

\section{References}

Akerlof, G. A., and Dickens, W. T. (1982) "The Economic Consequences of Cognitive Dissonance," American Economic Review, 72(3): 307-319.

Akerlof, G. A., and Kranton, R. E. (2000) "Economics and Identity," Quarterly Journal of Economics 115(3), 715-753.

Andreoni, J., and Sanchez, A. (2014) "Do Beliefs Justify Actions or Do Actions Justify Beliefs? An Experiment on Stated Beliefs, Revealed Beliefs, and Social-Image Motivation," working paper.

Babcock, L., and Loewenstein, G. (1997) "Explaining Bargaining Impasse: The Role of SelfServing Biases," Journal of Economic Perspectives 11(1): 109-126.

Bartling, B., and Özdemir, Y. (2017) "The Limits to Moral Erosion in Markets: Social Norms and the Replacement Excuse," working paper.

Bénabou, R. (2013) "Groupthink: Collective Delusions in Organizations and Markets," Review of Economic Studies, 80: 429-462. 
Bénabou, R., and Tirole, J. (2006) "Incentives and Prosocial Behavior," American Economic Review, 96(5): 1652-1678.

Bénabou, R., and Tirole, J. (2011). "Identity, Morals, and Taboos: Beliefs as Assets," Quarterly Journal of Economics, 126: 805-855.

Bénabou, R., and Tirole, J. (2016) "Mindful Economics: The Production, Consumption, and Value of Beliefs," Journal of Economic Perspectives, 30(3): 141-164.

Bock, O., Baetge, I., and Nicklisch, A. (2014) "hroot: Hamburg registration and organization online tool," European Economic Review, 71: 117-120.

Bodner, R., and Prelec, D. (2002) "Self-Signaling and Diagnostic Utility in Everyday Decision-Making," in Brocas, I. and Carrillo, J. eds., Collected Essays in Psychology and Economics, Oxford, UK: Oxford University Press.

Bodner, R., and Prelec, D. (2003) "Self-Signaling and Diagnostic Utility in Everyday Decision-Making," in Loewenstein, G., Read, D. and Baumeister, R.F. eds., Time and Decision, New York: Russell Sage Press.

Brunnermeier, M. K., and Parker, J. A. (2005) “Optimal Expectations," American Economic Review 95(4): 1092-1118.

Camerer, C., Loewenstein, G., and Weber, M. (1989) "The Curse of Knowledge in Economic Settings: An Experimental Analysis," Journal of Political Economy, 97(5): 12321254.

Chen, Z., and Gesche, T. (2017) "Persistent Bias in Advice-Giving," working paper.

Dana, J., Weber, R. A., and Kuang, J. X. (2007) "Exploiting moral wiggle room: experiments demonstrating an illusory preference for fairness," Economic Theory, 33(1): 67-80.

Di Tella, R., Perez-Truglia, R., Babino, A., and Sigman, M. (2015) "Conveniently Upset: Avoiding Altruism by Distorting Beliefs about Others' Altruism," American Economic Review, 105(11): 3416-42.

Eil, D., and Rao, J. M. (2011) "The Good News-Bad News Effect: Asymmetric Processing of Objective Information about Yourself," American Economic Journal: Microeconomics, 3(2): 114-138.

Exley, C. (2016) "Excusing Selfishness in Charitable Giving: The Role of Risk," Review of Economics Studies, 83(2): 587-628.

Fischbacher, U. (2007) "z-Tree: Zurich toolbox for ready-made economic experiments," Experimental Economics, 10(2): 171-178.

Fischbacher, U., Gächter, S., and Fehr, E. (2001) "Are people conditionally cooperative? Evidence from a public goods experiment," Economics letters 71(3): 397-404.

Fischbacher, U., and Gächter, S. (2010) "Social Preferences, Beliefs, and the Dynamics of Free Riding in Public Goods experiments," American Economic Review, 100(1): 541-556.

Gino, F., Norton, M. I., and Weber, R. A. (2016) "Motivated Bayesians: Feeling Moral While Acting Egoistically," Journal of Economic Perspectives, 30(3): 189-212.

Gneezy, U., Saccardo, S., Serra-Garcia, M., and Van Veldhuizen, R. (2018) "Bribing the Self," working paper.

Grossman, Z. J., and van der Weele, J. (2017) "Self-Image and Willful Ignorance in Social Decisions,” Journal of the European Economic Association, 15(1): 173-217.

Haisley, E., and Weber, R. A. (2010) "Self-serving interpretations of ambiguity in otherregarding behavior," Games and Economic Behavior, 68(2): 634-645. 
Hamman, J., Loewenstein, G., and Weber, R. A. (2010) "Self-interest through delegation: An additional rationale for the principal-agent relationship," American Economic Review, 100(4): 1826-1846.

Irwin, F. W. (1953) "Stated Expectations as Functions of Probability and Desirability of Outcomes," Journal of Personality, 21(3): 329-335.

Jecker, J., and Landy, D. (1969) "Liking a person as a function of doing him a favor," Human Relations, 22: 371-378.

Konow, J. (2000) "Fair Shares: Accountability and Cognitive Dissonance in Allocation Decisions," American Economic Review, 90(4): 1072-1091.

Kunda, Z. (1990) “The Case for Motivated Reasoning,” Psychological Bulletin, 108(3): 48098.

Langer, E. J. (1975) "The Illusion of Control," Journal of Personality and Social Psychology, 32(2): 311-328.

Lerner, M. J. (1980) "The Belief in a Just World: A Fundamental Delusion." New York: Plenum Press.

Levine, D. K. (1998) "Modeling Altruism and Spitefulness in Experiments," Review of Economic Dynamics, 1: 593-622.

Madarász, K. (2012) "Information Projection: Model and Applications," Review of Economic Studies, 79: 961-985.

Mayraz, G. (2013) "Wishful Thinking," working paper.

Mazar, N., Amir, O., and Ariely, D. (2008) "The Dishonesty of Honest People: A Theory of Self-Concept Maintenance," Journal of Marketing Research, 45(6): 633-644.

Möbius, M. M., Niederle, M., Niehaus, P., and Rosenblat, T. S. (2017) "Managing SelfConfidence," working paper.

OECD (2018) "Purchasing power parities (PPP) (indicator)," Accessed on 21 August 2018.

Quatrone, G. A., and Tversky, A. (1984) "Causal versus diagnostic contingencies: On selfdeception and on the voter's illusion," Journal of Personality and Social Psychology, 46(2): 237-248.

Rabin, M. (1993) "Incorporating Fairness into Game Theory and Economics," American Economic Review, 83(5): 1281-1302.

Rabin, M. (1994) "Cognitive dissonance and social change," Journal of Economic Behavior and Organization, 23: 177-194.

Schopler, J., and Compere, J. S. (1971) "Effects of being kind or harsh to another on liking," Journal of Personality and Social Psychology, 20(2): 155-159.

Schwardmann, P., and van der Weele, J. (2016) "Deception and Self-Deception," working paper.

Shalvi, S., Gino, F., Barkan, R., and Ayal S. (2015) "Self-serving Justifications: Doing Wrong and Feeling Moral," Current Directions in Psychological Science 24(2): 125130.

Svenson, O. (1981) "Are we all less risky and more skillful than our fellow drivers?," Acta Psychologica, 47: 143-148.

Taylor, S. E., and Brown, J. D. (1988) "Illusion and Well-Being: A Social Psychological Perspective on Mental Health," Psychological Bulletin, 103(2): 193-210.

Trivers, R. (2011) "The Folly of Fools: The Logic of Deceit and Self-Deception in Human Life,” New York: Basic Books. 
van der Weele, J. Kulisa, J., Kosfeld, M., and Friebel, G. (2014) "Resisting Moral Wiggle Room: How Robust Is Reciprocal Behavior?," American Economic Journal: Microeconomics, 6(3): 256-264.

Weinstein, N. D. (1980) "Unrealistic optimism about future life events," Journal of Personality and Social Psychology, 39(5): 806-820.

Weinstein, N. D. (1989) “Optimistic Biases About Personal Risks,” Science, 246: 1232-1233. Zimmerman, F. (2018) “The Dynamics of Motivated Beliefs," working paper. 


\section{Appendix A: Additional results}

Figure A1 - Distribution of Player A choices in Experiment 1

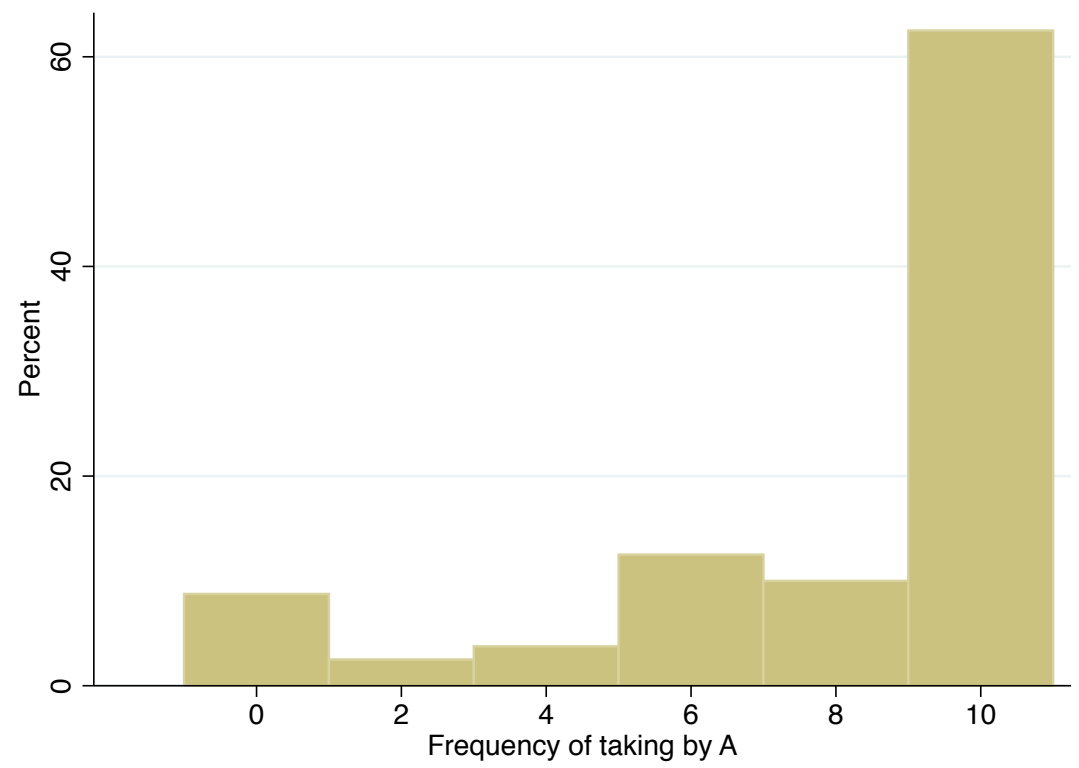

Figure A2 - Distribution of Player B choices in Experiment 2

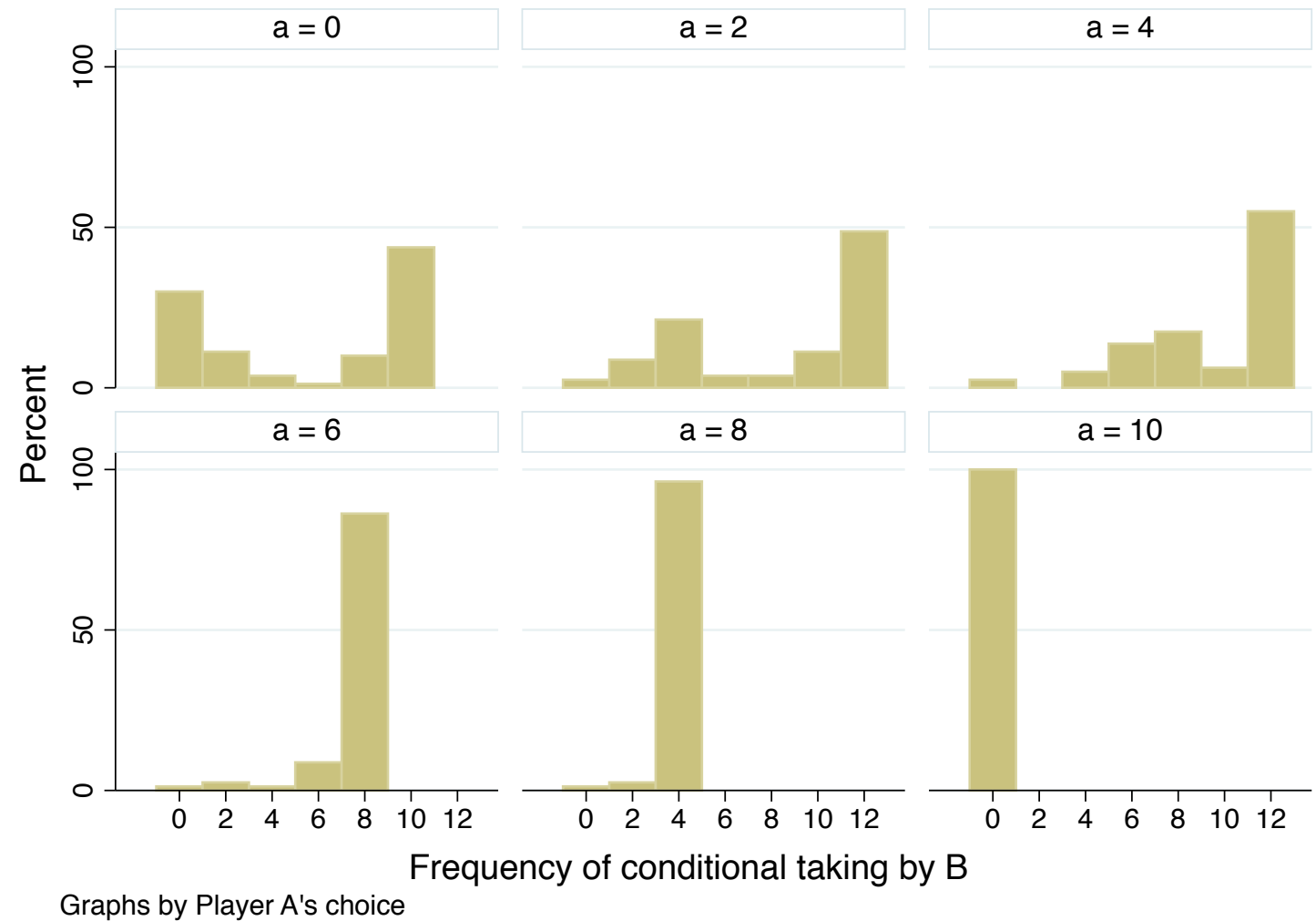


Figure A3 - Taking by Player A and corresponding beliefs of Players B and C

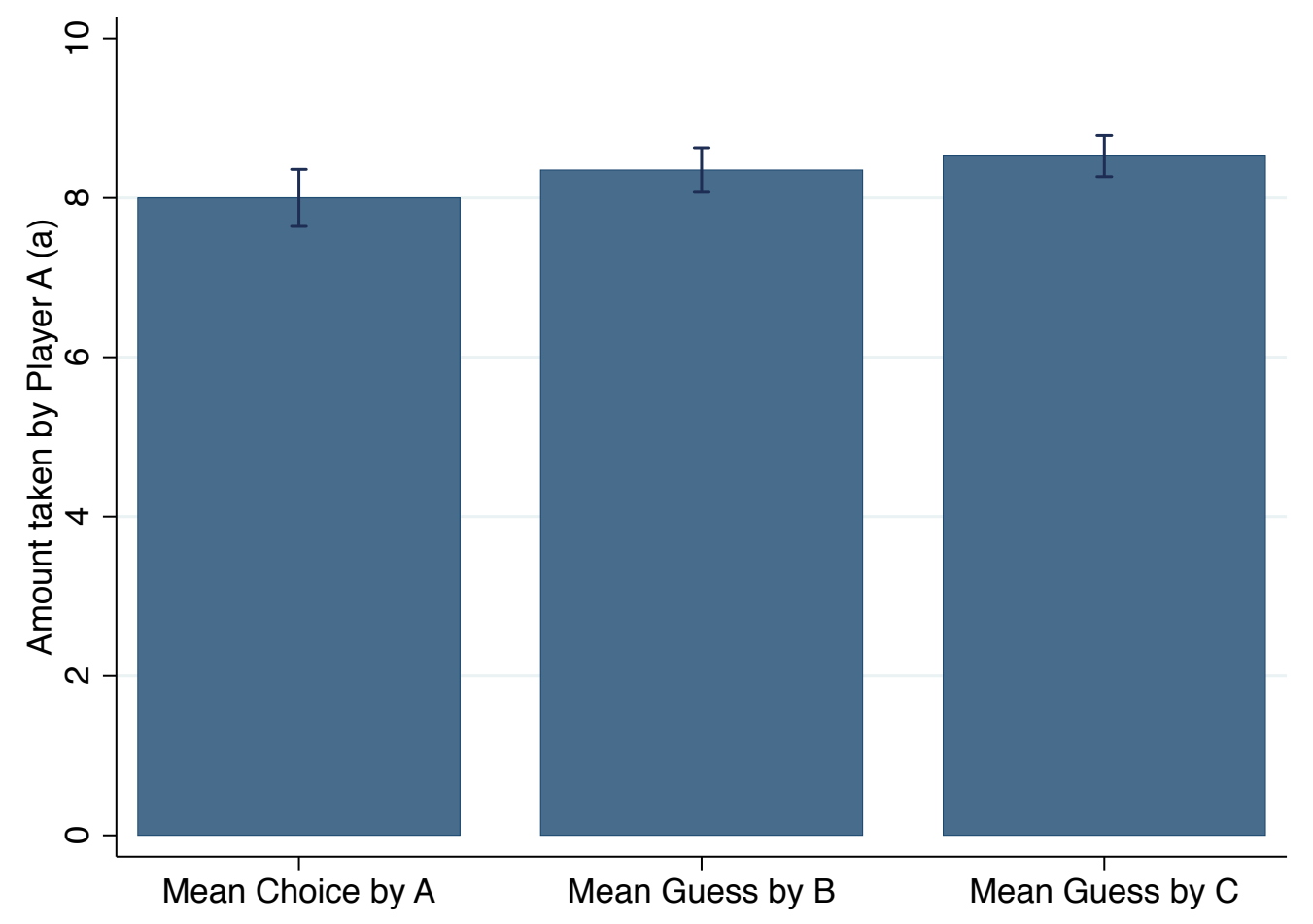




\section{Appendix B: Proofs}

Proposition 1: For any $(x, \hat{p})$ in $\operatorname{argmax}_{x \in[0, K], \hat{p} \in[0,1]} \mathrm{U}(x, \hat{p}), \hat{p} \leq p$.

Proof: For any $\hat{p} \in(p, 1]$ and any $x \in[0, K]$ we have that $U(x, p)>U(x, \hat{p})$ :

$$
\begin{gathered}
U(x, p)-U(x, \hat{p})=\left(E_{p}(d)-E_{\hat{p}}(d)\right) v(1-x) \\
+(C(\hat{p}-p)-C(0))+(P(0)-P(\hat{p}-p))
\end{gathered}
$$

First, note that $\left(E_{p}(d)-E_{\hat{p}}(d)\right) v(1-x)>0$ as $E_{p}(d)>E_{\hat{p}}(d)$ and $v()>$.0 . Second, we have $C(\hat{p}-p)-$ $C(0)>0$ as $C^{\prime}()>$.0 . Third, $P^{\prime}()<$.0 implies that $P(0)-P(\hat{p}-p)>0$. Therefore $U(x, p)-U(x, \hat{p})>0$, and $\hat{p} \in(p, 1]$ cannot be a solution to (1).

Proposition 2: Take $K, K^{\prime}$ in $(0,1]$ with $K^{\prime}<K$ and suppose that there is a unique solution to (1) for both $K$ and $K^{\prime}$, then $\hat{p}^{\prime} \leq \hat{p}$.

Proof: Define $(x, \hat{p})=\operatorname{argmax}_{x \in[0, K], \hat{p} \in[0,1]} \mathrm{U}(x, \hat{p})$ and $\left(x^{\prime}, \hat{p}^{\prime}\right)=\operatorname{argmax}_{x \in\left[0, K^{\prime}\right], \hat{p} \in[0,1]} \mathrm{U}(x, \hat{p})$.

Case i) Suppose $x \leq K^{\prime}$, then $(x, \hat{p})$ is the solution of $\max _{x \in\left[0, K^{\prime}\right], \hat{p} \in[0,1]} U(x, \hat{p})$, so $\hat{p}^{\prime}=\hat{p}$.

Case ii) Suppose $x(K)>K^{\prime}$. Then $x\left(K^{\prime}\right)<x(K)$ (and $1-x\left(K^{\prime}\right)>1-x(K)$ ). Note that the relevant Karush-Kuhn-Tucker conditions for the problem are (Proposition 1 implies that the condition $\hat{p} \leq 1$ is not binding):

$$
\begin{gathered}
-\mathrm{P}^{\prime}(p-\hat{p})-\left(d_{H}-d_{L}\right) v(1-x)+C^{\prime}(p-\hat{p})+\lambda=0 \text { (I) } \\
\lambda \hat{p}=0 \text { (II) } \\
\hat{p} \geq 0 \text { (III) } \\
\lambda \geq 0 \text { (IV) }
\end{gathered}
$$

Case iia) Suppose $\hat{p}^{\prime}=0$, then $\hat{p}^{\prime} \leq \hat{p}$ due to condition (III).

Case iib) Suppose $\hat{p}=0$. Then (I) implies

$$
\left(d_{H}-d_{L}\right) v(1-x) \geq C^{\prime}(p)-\mathrm{P}^{\prime}(p)\left(\mathrm{I}^{\prime}\right)
$$

Note that $\left(d_{H}-d_{L}\right) v\left(1-x^{\prime}\right)>\left(d_{H}-d_{L}\right) v(1-x)$ as $v^{\prime}()>$.0 . This, together with (I') and the assumptions on $\mathrm{C}$ and $\mathrm{P}$ imply $\left(d_{H}-d_{L}\right) v\left(1-x^{\prime}\right)>C^{\prime}(p)-\mathrm{P}^{\prime}(p) \geq C^{\prime}\left(p-\hat{p}^{\prime}\right)-\mathrm{P}^{\prime}\left(p-\hat{p}^{\prime}\right)$. Then by (I), $\lambda^{\prime}>0$. Then by (II) $\hat{p}^{\prime}=0$.

Case iic) Suppose $\hat{p}, \hat{p}^{\prime}>0$. Then by (II) $\lambda=\lambda^{\prime}=0$. Then (I) simplifies to:

$$
\begin{gathered}
\left(d_{H}-d_{L}\right) v(1-x)=C^{\prime}(p-\hat{p})-\mathrm{P}^{\prime}(p-\hat{p})\left(\mathrm{I}^{\prime \prime}\right) \\
\left(d_{H}-d_{L}\right) v\left(1-x^{\prime}\right)=C^{\prime}\left(p-\hat{p}^{\prime}\right)-\mathrm{P}^{\prime}\left(p-\hat{p}^{\prime}\right)\left(\mathrm{I}^{\prime \prime \prime}\right)
\end{gathered}
$$

Combining (I'), (I"') and $\left(d_{H}-d_{L}\right) v\left(1-x^{\prime}\right)>\left(d_{H}-d_{L}\right) v(1-x)$ implies:

$$
C^{\prime}\left(p-\hat{p}^{\prime}\right)-\mathrm{P}^{\prime}\left(p-\hat{p}^{\prime}\right)>C^{\prime}\left(p-\hat{p}^{\prime}\right)-\mathrm{P}^{\prime}(p-\hat{p})(V)
$$

(V) together with $P^{\prime}()<0,. P^{\prime \prime}() \leq 0,. C^{\prime}()>$.0 and $C^{\prime \prime}()>$.0 implies $\hat{p}^{\prime} \leq \hat{p}$.

Proposition 3: $\hat{p}^{N}=p$ is the unique solution to $\max _{\hat{p}^{N} \in[0,1]} U\left(\hat{p}^{N}\right)$.

Proof: For any $\hat{p}^{N} \in(p, 1]$ we have that $U(p)-U\left(\hat{p}^{N}\right)=P(0)-P\left(\hat{p}^{N}-p\right)+C\left(\hat{p}^{N}-p\right)-C(0)>0$ due to $C^{\prime}()>$.0 and $P^{\prime}()<$.0 .

For any $\hat{p}^{N} \in[0, p)$ we have that $U(p)-U\left(\hat{p}^{N}\right)=P(0)-P\left(p-\hat{p}^{N}\right)+C\left(p-\hat{p}^{N}\right)-C(0)>0$ due to $C^{\prime}()>$.0 and $P^{\prime}()<$.0 . 


\section{Appendix C: Instructions}

\section{Pre-emptive taking game: Instructions Wave 1 (sessions 1 - 4)}

\subsection{Initial Instructions}

Thank you for participating in today's experiment. I will read through a script to explain to you the nature of today's experiment as well as how to navigate the computer interface with which you will be working.

[Experimenter Only: You will see the instructions on the screen in front of you. Please read along as I read them aloud. If your screen is blank, please move the mouse to activate it.]

If you have any questions during the experiment, please raise your hand and wait for an experimenter to come to you. Please do not talk, exclaim, or try to communicate with other participants during the experiment.

Participants intentionally violating the rules may be asked to leave the experiment with only the show-up fee.

\section{Please click "Continue" once the experimenter asks you to do so.}

[CONTINUE]

\subsection{Roles}

In today's experiment, you will be randomly assigned to one of three roles: A, B or C. Below, you see the role to which you have been assigned in the experiment. Your role will remain the same for the duration of the experiment.

\section{Your role for today is:}

Every participant receives a CHF 10 show-up fee. This payment will be added to any amount that you accumulate in the experiment. The final amount you end up with may vary, depending on your decisions and the decisions of others.

Each Participant A will be randomly paired with one Participant B and the two will make decisions that can affect how much money each of the two participants ends up with. No participant will be told the identity of any other person. In particular, if you are a Participant A or B, you will not be told the identity of the person with whom you are paired, and this person will not be told your identity. Subjects in the role of Participant $\mathrm{C}$ are not matched with anybody and will not make any decisions that impact other participants in the experiment. However, each Participant $\mathrm{C}$ can earn additional money based on choices that will be described later. In particular, Participants $\mathrm{C}$ will make guesses about the decisions made by other participants. For this reason, Participants $\mathrm{C}$ should pay close attention to the instructions for Participants A and B.

Please click "Continue" to proceed to the next screen.

[CONTINUE] 


\subsection{Instructions}

In today's experiment, each Participant A is randomly paired with a Participant B. Each person in the pair will make a single decision affecting themselves and their paired counterpart. They will also each make a guess about what choice the other participant will make. For the accuracy of their guess, participants can earn additional money.

These will be the only choices Participants A and B will make in the experiment and will determine how much money they receive at the end of the experiment, in addition to the CHF 10 show-up fee.

Both Participants A and B start with an initial endowment of 10 chips. They will each make a decision that can affect how many chips the two participants end up with. At the end of the experiment, the chips each participant has will be converted into CHF at the rate of $\mathbf{1}$ chip $=\mathbf{C H F}$ 1.50. This amount is in addition to the CHF 10 show-up fee. Note that the amount that these participants end up with can vary based on the decisions they make.

We will now provide you with instructions for the decisions by Participants A and B. We will then describe the guesses that all participants will make.

Please click "Continue" to proceed to the next screen.

[CONTINUE]

\section{Decisions}

Stage 1: Participant A's decision

Participant A first decides how many chips to take from Participant B's endowment of 10 chips. Let us refer to the amount Participant A takes from Participant B as $a$. Participant A can take any multiple of 2 chips, $a$, from 0 chips to the full endowment of 10 chips. That is, Participant A can choose to take any of the amounts: 0 chips, 2 chips, 4 chips, 6 chips, 8 chips, or 10 chips.

At the end of Stage 1, Participants A and B will end up with the following numbers of chips:

- Participant A: $10+a$

- Participant B: $10-a$

Stage 2: Participant B's decision

Following Participant A's decision, Participant $B$ will then decide how many chips to take from Participant A.

Let us refer to the amount Participant B takes from Participant A as $2 b$. The amount that Participant B can take from Participant A depends on how much Participant B has left at the end of Stage 1.

Specifically, for every 2 chips Participant B takes from Participant A, Participant B has to spend 1 chip. So, we can define $b$ as the amount Participant B must spend to take $2 b$ chips from Participant A. Participant $B$ can only spend and take based on the number of chips he or she has available at the end of Stage 1. So, if Participant B has no chips left at the end of Stage 1, then he or she cannot take any chips from Participant A. If Participant B has some number, $b$, of chips available at the end of Stage 1, then Participant B can choose to take any number of chips from 0 up to $2 b$ from Participant A in Stage 2.

At the end of Stage 2, Participants A and B will end up with the following numbers of chips:

- Participant A: $10+a-2 b$

- Participant B: $10-a+2 b-b$

where:

$a$ is the amount taken from Participant B by Participant A in Stage 1

$2 b$ is the amount taken from Participant A by Participant B in Stage 2

$b$ is the amount Participant B has to spend to take $2 b$ from Participant A in Stage 2

So, for example, suppose Participant A took 6 chips in Stage 1. Then $a$ equals 6 . This means that at the beginning of Stage 2, Participant A has 16 chips and Participant B has 4 chips. Then Participant B can spend up to 4 chips to take up to 8 chips from Participant A. In order to take 8 chips, Participant B has to spend all of his or her remaining 4 chips. This would leave Participant A with 8 chips and Participant B with 8 chips at the end of Stage 2 . 
To give another example, suppose instead that Participant A took 8 chips in Stage 1. Then $a$ equals 8 . This means that at the beginning of Stage 2, Participant A has 18 chips and Participant B has 2 chips. Then Participant B can spend up to 2 chips to take up to 4 chips from Participant A. In order to take 4 chips, Participant B has to spend all of his or her remaining 2 chips. This would leave Participant A with 14 chips and Participant B with 4 chips at the end of Stage 2.

As a final example, suppose that Participant B has 0 chips at the beginning of Stage 2, because Participant A took all 10 chips in Stage 1. Then Participant B cannot take anything from Participant $\mathrm{A}$, since he or she has no chips to spend on taking. In this case, $2 b$ has to equal 0 and Participant A keeps everything he or she took. This leaves Participant A with 20 chips and Participant B with 0 chips.

Note that there are the following two restrictions for Participant B:

1) Participant B cannot spend more chips than he or she has available in Stage 2.

This means that Participant B has to have at least $b$ chips at the end of Stage 1 in order to take $2 b$ chips from Participant A. The amount that Participant B can take from Participant A in Stage 2 depends on how much Participant B is left with at the end of Stage 1. That is, by choosing how much to take in Stage $1(a)$, Participant A can affect how much Participant B can take in Stage 2.

2) Participant B cannot take more chips than Participant A has available after Stage 1 $(2 b \leq 10+a)$. So, for example, imagine that both participants have 10 chips at the beginning of Stage 2, because Participant A took 0 chips in Stage 1. In this case, $2 b$ cannot be greater than 10. This means that the most Participant B can take is 10 chips, in which case Participant B has to spend 5 chips to do so.

Please click "Continue" to proceed to the next screen.

[CONTINUE]

\section{Guesses}

In addition to the above decisions, Participants $\mathrm{A}$ and $\mathrm{B}$ will guess what choices the participant with whom they are paired will make in the experiment. Participants $C$, who do not make any other choices in the experiment, will make guesses about the decisions made by both Participants A and B. All Participants will receive money for making these guesses accurately.

Please click "Continue" to proceed to the next screen.

[CONTINUE]

\section{Procedure of decisions [displayed to all]}

We are now going to provide you with instructions for the procedures you will use to make your decisions.

\section{Entering choices}

In a moment, you will each see a decision screen. This screen will present a table similar to the one you have on your desk. [Experimenter only: Please turn over the sheet next to you.] This table displays all possible choices available to Participants A and B. On the decision screen, both Participants A and B will make their choices by indicating them on a table like this.

Please take a moment to look at this table carefully, since your earnings will depend on understanding this table. We will now describe the table and how choices are entered in more detail. Please look at the table on your desk while we do this.

\section{Participant A's decision}

The first column, labeled "Participant A's decision in Stage 1," presents all possible decisions $(a)$ that Participant A can choose in Stage 1. Specifically, each row represents one possible decision available 
to Participant A. Participant A can choose whether to take 0 chips, 2 chips, 4 chips, 6 chips, 8 chips or 10 chips from Participant B. Participant A makes this choice by selecting one of the boxes in the first column.

The next column provides the number of chips with which Participant B is left at the end of Stage 1 . This is also the number of chips Participant B has available to spend in Stage 2.

\section{Participant B's decision}

The final column, labeled "Participant B's options in Stage 2," presents a series of sub-tables, one for each possible amount that Participant B has available in Stage 2. These tables describe all of the possible choices that Participant B can make, given that particular decision by Participant A in Stage 1. In each sub-table, you see all the possible amounts Participant B can take from Participant A (2b) and how much Participant B would have to spend to take that amount $(b)$. You also see the final payoffs, in chips, for both Participants A and B.

In the table on the decision screen, Participant B will make a choice for each sub-table by indicating one possible action he wants to have implemented if that sub-table is the one that counts. The actual sub-table that counts will be determined by what Participant A chooses. That is, every possible choice $a$, by Participant A in Stage 1, leaves Participant B with some amount of chips $(10-a)$ at the beginning of Stage 2. For each possible remaining amount $(10-a)$, Participant B will be able to specify how many chips $(2 b)$ he or she wishes to take from Participant A in Stage 2 by selecting one box in that particular sub-table.

\section{Examples}

Consider for example, if Participant A takes 0 chips in Stage 1, shown by the first row $(a=0)$. This leaves both Participants A and B with 10 chips at the end of Stage 1. Then, Participant B can spend up to 10 chips on taking from Participant A. Remember the restriction that Participant B cannot take more chips than Participant A has available. So, Participant B cannot take more than 10 chips from Participant A. Thus, the possible amounts Participant B can take, $2 \mathrm{~b}$, ranges from 0 to 10 chips. Suppose for example, that Participant A takes 6 chips in Stage 1, shown by the fourth row $(a=6)$. This leaves Participant A with 16 chips and Participant B with 4 chips at the end of Stage 1. So, Participant B can spend at most 4 chips on taking from Participant A $(b \leq 4)$ and can take at most 8 chips $(2 b \leq 8)$ from Participant A. If Participant B takes 8 chips, the final payoff for Participant A is 8 chips and for Participant $\mathrm{B}$ it is 8 chips.

Please click "Continue" to proceed to the next screen.

[CONTINUE]

\section{Summary [displayed to all]}

Before we show you the decision screen, we now summarize for each Participant A, B or C, the choices that he or she will make and we describe how they will be made on the decision screen. This summary is also provided for you on a sheet of paper at your desk.

Overview of decisions

- Participant A and Participant B each start with 10 chips. Each chip is worth CHF 1.5.

- In Stage 1, Participant A decides how many chips $(a)$ to take from Participant B.

- In Stage 2, Participant B then decides how many chips (2b) to take from Participant A. For every $2 b$ chips Participant B takes from Participant A, Participant B has to spend $b$ chips. Participant B is therefore constrained by the number of chips he or she has available at the end of Stage 1.

At the end of Stage 2, Participants A and B will end up with the following numbers of chips:

- Participant A: $10+a-2 b$

- Participant B: $10-a+2 b-b$ 


\section{Participant A}

Participant A will both choose an amount to take from Participant B $(a)$ and will make guesses about how much his or her Participant B intends to take $(2 b)$. In particular:

Choice of how much to take: Participant A will choose a value of $a$ to take from Participant B in Stage 1 by selecting one box in the first column.

Guess of how much Participant B intends to take: In addition, Participant A will indicate how many chips he or she thinks his or her paired Participant B will take from him or her. Participant A will do so for each possible amount Participant B might have available at the beginning of Stage 2 .

Specifically, in the final column, "Participant B's options in Stage 2," Participant A will select one of the different options available to Participant B in each sub-table. Remember that the paired Participant $\mathrm{B}$ will indicate his or her choices in a table similar to this one.

At the end of the experiment, the computer will randomly select one of the amounts $(10-a)$ available to Participant B in Stage 2. Note that this might differ from the actual amount available to the paired Participant B in Stage 2. If Participant A's guess in that respective sub-table is the same number as what the paired Participant B actually indicated he or she would take, then Participant A will receive an additional payment of CHF 4.

\section{Participant B}

Participant B will both indicate how much he or she would like to take from Participant A $(2 b)$ and will make a guess about how much Participant A will take $(a)$. In particular: Choice of how much to take: Each row of the table presents the possible amount with which Participant B could end up at the beginning of Stage 2 (10 chips, 8 chips, 6 chips, . ., 0 chips) based on the Stage-1 decision of the paired Participant A. Without knowing yet which amount Participant A actually chose to take, Participant B will decide how much he or she wishes to take from Participant A in Stage $2(2 b)$ for each possible row. Specifically, Participant B will make a choice by selecting for each sub-table in the fourth column one possible action to take. Depending on the actual amount $a$ chosen by Participant A, the corresponding row will be selected to count. That is, Participant A's choice in Stage 1 determines the actual number of chips Participant B has at the beginning of Stage 2 $(10-a)$. Participant B's selected box of how much to take, $2 b$, in that respective sub-table will be implemented as Participant B's actual choice. So, the actual amount that Participant B takes from Participant A depends on two things: i) the chosen $a$ by Participant A determines which row counts, ii) the chosen $2 b$ by Participant $B$ determines which option in the sub-table of that respective row counts.

Guess of how much Participant A will take: In addition, Participant B will guess what value of $a$ his or her paired Participant A will take in Stage 1, Participant B will do so by selecting one particular box in the first column. If Participant B's guess is the same as the number chosen by the paired Participant A, then Participant B will receive an additional payment of CHF 4.

\section{Participant C}

Participant $\mathrm{C}$ will not make any choices that affect other participants in the experiment. Instead, Participant $\mathrm{C}$ will start with CHF 15, in addition to the CHF 10 show-up fee. Furthermore, Participant $\mathrm{C}$ will have the opportunity to make additional money by guessing what values of $a$ and $2 b$ Participants A and B will choose in the experiment. In particular:

Guess of how much Participant A will take: Each Participant $\mathrm{C}$ will guess what value of $a$ a randomly selected Participant A will take in Stage 1. Participant $C$ will do so by selecting one particular box in the first column. If Participant C's guess is the same as the number chosen by that randomly selected Participant A, then Participant $\mathrm{C}$ will receive an additional payment of CHF 4.

Guess of how much Participant B intends to take: In addition, each Participant $C$ will indicate how many chips he or she thinks a randomly selected Participant B will take from the paired Participant A. Participant $\mathrm{C}$ will do so for each possible amount Participant B might have available at the beginning of Stage 2. Specifically, in the final column, "Participant B's options in Stage 2," Participant C will select one of the different options available to Participant B in each sub-table. Remember that the randomly selected Participant B will indicate his or her choices in a table similar to this one. 
At the end of the experiment, the computer will randomly select one of the amounts $(10-a)$ available to Participant B in Stage 2. Note that this might differ from the actual amount available to that randomly selected Participant B in Stage 2. If Participant C's guess in that respective sub-table is the same number as what the randomly selected Participant B actually indicated he or she would take, then Participant $\mathrm{C}$ will receive an additional payment of CHF 4.

Please click "Continue" to proceed to the "decision screen."

[CONTINUE]

Decision Screen [all Individuals are shown the same table]

Your role: [ID]

\begin{tabular}{|c|c|c|c|c|c|c|c|c|c|c|}
\hline \multicolumn{2}{|c|}{$\begin{array}{l}\text { Your choice in Stage } 1 \text { (a) / } \\
\text { Your guess of Participant A's } \\
\text { choice in Stage } 1 \text { (a) }\end{array}$} & \multirow{5}{*}{$\begin{array}{c}\begin{array}{c}\text { Amount } \\
\text { Participant B } \\
\text { has available in } \\
\text { Stage } 2 \\
(10-a)\end{array} \\
10\end{array}$} & \multicolumn{8}{|c|}{$\begin{array}{l}\text { Participant B's options in Stage 2/ Your options in Stage 2: } \\
\text { Please enter for each row your guess of Participant B's choice } \\
\text { in Stage } 2 \text { (2b) / } \\
\text { Please enter for each row your choice ( } 2 \mathrm{~b})\end{array}$} \\
\hline \multirow{4}{*}{ O } & \multirow{4}{*}{0} & & Participant B's decision & 0 & 0 & 0 & 0 & 0 & O & \\
\hline & & & Taking (2b) & 0 & 2 & 4 & 6 & 8 & 10 & \\
\hline & & & Final Payoff A (in chips) & 10 & 8 & 6 & 4 & 2 & 0 & \\
\hline & & & Final Payoff B (in chips) & 10 & 12 & 14 & 16 & 18 & 20 & \\
\hline \multirow{4}{*}{ O } & \multirow{4}{*}{2} & \multirow{4}{*}{8} & Participant B's decision & 0 & 0 & 0 & 0 & 0 & 0 & 0 \\
\hline & & & Taking (2b) & 0 & 2 & 4 & 6 & 8 & 10 & 12 \\
\hline & & & Final Payoff A (in chips) & 12 & 10 & 8 & 6 & 4 & 2 & 0 \\
\hline & & & Final Payoff B (in chips) & 8 & 10 & 12 & 14 & 16 & 18 & 20 \\
\hline \multirow{4}{*}{ O } & \multirow{4}{*}{4} & \multirow{4}{*}{6} & Participant B's decision & 0 & 0 & 0 & 0 & 0 & O & O \\
\hline & & & Taking (2b) & 0 & 2 & 4 & 6 & 8 & 10 & 12 \\
\hline & & & Final Payoff A (in chips) & 14 & 12 & 10 & 8 & 6 & 4 & 2 \\
\hline & & & Final Payoff B (in chips) & 6 & 8 & 10 & 12 & 14 & 16 & 18 \\
\hline \multirow{4}{*}{ O } & \multirow{4}{*}{6} & \multirow{4}{*}{4} & Participant B's decision & 0 & 0 & 0 & 0 & 0 & & \\
\hline & & & Taking (2b) & 0 & 2 & 4 & 6 & 8 & & \\
\hline & & & Final Payoff A (in chips) & 16 & 14 & 12 & 10 & 8 & & \\
\hline & & & Final Payoff B (in chips) & 4 & 6 & 8 & 10 & 12 & & \\
\hline \multirow{4}{*}{ ○ } & \multirow{4}{*}{8} & \multirow{4}{*}{2} & Participant B's decision & 0 & 0 & 0 & & & & \\
\hline & & & Taking (2b) & 0 & 2 & 4 & & & & \\
\hline & & & Final Payoff A (in chips) & 18 & 16 & 14 & & & & \\
\hline & & & Final Payoff B (in chips) & 2 & 4 & 6 & & & & \\
\hline \multirow{4}{*}{ O } & \multirow{4}{*}{10} & \multirow{4}{*}{0} & Participant B's decision & 0 & & & & & & \\
\hline & & & Taking (2b) & 0 & & & & & & \\
\hline & & & Final Payoff A (in chips) & 20 & & & & & & \\
\hline & & & Final Payoff B (in chips) & 0 & & & & & & \\
\hline
\end{tabular}

Once you have made your decision and you have filled in the table, please submit your decision by clicking "Continue." 


\section{Payment Screen [displayed to Individual A]}

\section{$\underline{\text { Payment }}$}

You have now finished the experiment.

\section{Decisions}

You decided to take $(a)$ _ chips from Participant B Participant B decided to take $(2 b)$ _ chips from you Your final chip total as a result of the decisions is: chips

This is worth CHF

\section{Guess}

Your guess in a randomly selected row is not the same as what your paired Participant B chose in that row, so you do not receive CHF 4 as additional compensation.

Your guess in a randomly selected row is the same as what your paired Participant B chose in that row, so you do receive CHF 4 as additional compensation.

\section{Your total payoff is:}

Before you are paid we ask you to fill out the questionnaire.

[CONTINUE]

\section{Payment Screen [displayed to Individual B]}

\section{$\underline{\text { Payment }}$}

You have now finished the experiment.

\section{Decisions}

Participant A decided to take $(a)$ _ chips from you In this case, your chosen amount to take from Participant $\mathrm{A}(2 b)$ is: Your final chip total as a result of the decisions is: chips

This is worth CHF

\section{Guess}

Your guess is not the same number as what your paired Participant A actually chose, so you do not receive $\mathrm{CHF} 4$ as additional compensation.

Your guess is the same number as what your paired Participant A actually chose, so you do receive CHF 4 as additional compensation.

\section{Your total payoff is:}

Before you are paid we ask you to fill out the questionnaire.

[CONTINUE]

\section{Payment Screen [displayed to Individual C]}


Payment

You have now finished the experiment.

\section{Guess about Participant A}

Your guess is not the same number as what a randomly selected Participant A actually chose, so you do not receive CHF 4 as additional compensation.

Your guess is the same number as what a randomly selected Participant A actually chose, so you do receive CHF 4 as additional compensation.

\section{Guess about Participant B}

Your guess in a randomly selected row is not the same as what a randomly selected Participant B actually chose, so you do not receive CHF 4 as additional compensation.

Your guess in a randomly selected row is the same as what a randomly selected Participant B actually chose, so you do receive CHF 4 as additional compensation.

\section{Your total payoff is:}

Before you are paid we ask you to fill out the questionnaire.

[CONTINUE] 
Possible Decisions by Participant A (first columns) and Participant B (final column)

\begin{tabular}{|c|c|c|}
\hline $\begin{array}{c}\text { Participant A's decision } \\
\text { in Stage 1: Amount taken } \\
\text { from Participant B (a) }\end{array}$ & $\begin{array}{c}\text { Amount Participant } \\
\text { B has available in } \\
\text { Stage 2 (10 - a) }\end{array}$ & Participant B's options in Stage 2 \\
\hline
\end{tabular}

\begin{tabular}{|c|c|c|c|c|c|c|c|c|c|}
\hline \multirow{5}{*}{ O } & \multirow{5}{*}{0} & \multirow{5}{*}{10} & Participant B's decision: & $\mathrm{O}$ & O & $\mathrm{O}$ & $\mathrm{O}$ & $\mathrm{O}$ & 0 \\
\hline & & & Amount spent on taking (b) & 0 & 1 & 2 & 3 & 4 & 5 \\
\hline & & & Amount taken from $A(2 b)$ & 0 & 2 & 4 & 6 & 8 & 10 \\
\hline & & & Final Payoff for A (in chips) & 10 & 8 & 6 & 4 & 2 & 0 \\
\hline & & & Final Payoff for B (in chips) & 10 & 11 & 12 & 13 & 14 & 15 \\
\hline
\end{tabular}

\begin{tabular}{|c|c|c|c|c|c|c|c|c|c|c|}
\hline \multirow{5}{*}{ O } & \multirow{5}{*}{2} & \multirow{5}{*}{8} & Participant B's decision: & O & O & O & O & O & $\bigcirc$ & $\bigcirc$ \\
\hline & & & Amount spent on taking (b) & 0 & 1 & 2 & 3 & 4 & 5 & 6 \\
\hline & & & Amount taken from $\mathrm{A}(2 \mathrm{~b})$ & 0 & 2 & 4 & 6 & 8 & 10 & 12 \\
\hline & & & Final Payoff for A (in chips) & 12 & 10 & 8 & 6 & 4 & 2 & 0 \\
\hline & & & Final Payoff for B (in chips) & 8 & 9 & 10 & 11 & 12 & 13 & 14 \\
\hline
\end{tabular}

\begin{tabular}{|c|c|c|c|c|c|c|c|c|c|c|}
\hline \multirow{5}{*}{ O } & \multirow{5}{*}{4} & \multirow{5}{*}{6} & Participant B's decision: & O & O & O & O & O & O & $\mathrm{O}$ \\
\hline & & & Amount spent on taking (b) & 0 & 1 & 2 & 3 & 4 & 5 & 6 \\
\hline & & & Amount taken from $\mathrm{A}(2 \mathrm{~b})$ & 0 & 2 & 4 & 6 & 8 & 10 & 12 \\
\hline & & & Final Payoff for A (in chips) & 14 & 12 & 10 & 8 & 6 & 4 & 2 \\
\hline & & & Final Payoff for B (in chips) & 6 & 7 & 8 & 9 & 10 & 11 & 12 \\
\hline
\end{tabular}

\begin{tabular}{|c|c|c|c|c|c|c|c|c|}
\hline \multirow{5}{*}{ O } & \multirow{5}{*}{6} & \multirow{5}{*}{4} & Participant B's decision: & O & O & O & O & O \\
\hline & & & Amount spent on taking (b) & 0 & 1 & 2 & 3 & 4 \\
\hline & & & Amount taken from $\mathrm{A}(2 \mathrm{~b})$ & 0 & 2 & 4 & 6 & 8 \\
\hline & & & Final Payoff for A (in chips) & 16 & 14 & 12 & 10 & 8 \\
\hline & & & Final Payoff for B (in chips) & 4 & 5 & 6 & 7 & 8 \\
\hline
\end{tabular}

\begin{tabular}{|c|c|c|c|c|c|c|}
\hline \multirow{5}{*}{ O } & \multirow{5}{*}{8} & \multirow{5}{*}{2} & Participant B's decision: & $\mathrm{O}$ & O & $\bigcirc$ \\
\hline & & & Amount spent on taking (b) & 0 & 1 & 2 \\
\hline & & & Amount taken from $\mathrm{A}(2 \mathrm{~b})$ & 0 & 2 & 4 \\
\hline & & & Final Payoff for A (in chips) & 18 & 16 & 14 \\
\hline & & & Final Payoff for B (in chips) & 2 & 3 & 4 \\
\hline
\end{tabular}

\begin{tabular}{|c|c|c|c|c|}
\hline \multirow{5}{*}{ O } & \multirow{5}{*}{10} & \multirow{5}{*}{0} & Participant B's decision: & 0 \\
\hline & & & Amount spent on taking (b) & 0 \\
\hline & & & Amount taken from $A(2 b)$ & 0 \\
\hline & & & Final Payoff for A (in chips) & 20 \\
\hline & & & Final Payoff for B (in chips) & 0 \\
\hline
\end{tabular}




\section{Pre-emptive taking game: Instructions Wave 2 (sessions 5 - 7)}

\subsection{Initial Instructions}

Thank you for participating in today's experiment.

[Experimenter Only:

I will read through a script to explain to you the nature of today's experiment as well as how to navigate the computer interface with which you will be working. Most of the instructions I will read are included in the paper sheets at your desk. At some points, I will ask you to look at information on your computer screen. If your screen is blank at any point, please move the mouse to activate it.] If you have any questions during the experiment, please raise your hand and wait for an experimenter to come to you. Please do not talk, exclaim, or try to communicate with other participants during the experiment.

Participants intentionally violating the rules may be asked to leave the experiment with only the show-up fee.

I will now read the instructions aloud. Please read along on the sheets at your desk.

Please click "Continue" once the experimenter asks you to do so.

[CONTINUE]

\subsection{Instructions}

\section{Roles and Decisions [paper only]}

In today's experiment, you will be randomly assigned to one of three roles: A, B or C. On your screen, you see the role to which you have been assigned in the experiment. Your role will remain the same for the duration of the experiment.

Every participant receives a CHF 10 show-up fee. This payment will be added to any amount that you accumulate in the experiment. The final amount you end up with may vary, depending on your decisions and the decisions of others.

Each Participant A will be randomly paired with one Participant B. No participant will be told the identity of any other person. If you are a Participant A or B, you will not be told the identity of the person with whom you are paired, and this person will not be told your identity.

In each pair, Participants A and B will each make a single decision that affects both people in the pair. They will also each make a guess about what choice the other participant will make. For the accuracy of their guess, Participants A and B can earn additional money. These will be the only decisions Participants A and B will make in the experiment and will determine how much money they receive at the end of the experiment, in addition to the CHF 10 show-up fee.

Participants in the role of Participant $\mathrm{C}$ are not matched with anybody and will not make any decisions that impact other participants in the experiment. However, Participants $\mathrm{C}$ will make guesses about the decisions made by Participants A and B. For the accuracy of their guesses, Participants C can earn additional money. For this reason, Participants $\mathrm{C}$ should pay close attention to the instructions for Participants A and B. 


\section{Decisions for Participants A and B [paper only]}

Both Participants A and B start with an initial endowment of 10 chips. They will each make a single decision that can affect how many chips the two participants end up with. They will only make this decision one time. At the end of the experiment, the chips each participant has will be converted into CHF at the rate of $\mathbf{1}$ chip $=\mathbf{C H F}$ 2.00. This amount is in addition to the CHF 10 show-up fee.

\section{Stage 1: Participant A’s decision}

Participant A first decides how many chips to take from Participant B's endowment of 10 chips. Let us refer to the amount Participant A takes from Participant B as $a$. Participant A can take any multiple of 2 chips, $a$, from 0 chips to the full endowment of 10 chips. That is, Participant A can choose to take any of the amounts: 0 chips, 2 chips, 4 chips, 6 chips, 8 chips, or 10 chips.

At the end of Stage 1, Participants A and B will end up with the following numbers of chips:

- Participant A: $10+a$

- Participant B: $10-a$

Stage 2: Participant B's decision

Following Participant A's decision, Participant $B$ will then decide how many chips to take from Participant A.

Let us refer to the amount Participant B takes from Participant A as $2 b$.

The amount that Participant B can take from Participant A depends on how much Participant B has left at the end of Stage 1. Specifically, for every 2 chips Participant B takes from Participant A, Participant B has to spend 1 chip. So, we can define $b$ as the amount Participant B must spend to take $2 b$ chips from Participant A. This means that Participant B can only spend and take based on the number of chips he or she has available at the end of Stage 1. So, if Participant B has no chips left at the end of Stage 1, then he or she cannot take any chips from Participant A. If Participant B has some number of chips, $10-a$, available at the end of Stage 1, then Participant B can choose to spend $b$ chips, up to where $b$ equals at most $10-a$, in order to take $2 b$ chips from Participant A in Stage 2. At the end of Stage 2, Participants A and B will end up with the following numbers of chips:

- Participant A: $10+a-2 b$

- Participant B: $10-a+2 b-b$

where:

$a$ is the amount taken from Participant B by Participant A in Stage 1

$2 b$ is the amount taken from Participant A by Participant B in Stage 2

$b$ is the amount Participant B has to spend to take $2 b$ from Participant A in Stage 2

So, for example, suppose Participant A took 4 chips in Stage 1. Then $a$ equals 4. This means that at the beginning of Stage 2, Participant A has 14 chips and Participant B has 6 chips. Then Participant B can spend up to 6 chips to take up to 12 chips from Participant A. In order to take 12 chips, Participant B has to spend all of his or her remaining 6 chips. This would leave Participant A with 2 chips and Participant B with 12 chips at the end of Stage 2.

To give another example, suppose instead that Participant A took 8 chips in Stage 1. Then $a$ equals 8 . This means that at the beginning of Stage 2, Participant A has 18 chips and Participant B has 2 chips. Then Participant B can spend up to 2 chips to take up to 4 chips from Participant A. In order to take 4 chips, Participant B has to spend all of his or her remaining 2 chips. This would leave Participant A with 14 chips and Participant B with 4 chips at the end of Stage 2.

As a final example, suppose that Participant B has 0 chips at the beginning of Stage 2, because Participant A took all 10 chips in Stage 1. Then Participant B cannot take anything from Participant $\mathrm{A}$, since he or she has no chips to spend on taking. In this case, $2 b$ has to equal 0 and Participant A 
keeps everything he or she took. This would leave Participant A with 20 chips and Participant B with 0 chips at the end of Stage 2.

Note that there are the following two restrictions for Participant B:

3) Participant B cannot spend more chips than he or she has available in Stage 2.

This means that Participant B has to have at least $b$ chips at the end of Stage 1 in order to take $2 b$ chips from Participant A. The amount that Participant B can take from Participant A in Stage 2 thus depends on how much Participant B is left with at the end of Stage 1. That is, by choosing how much to take in Stage 1, Participant A can affect how much Participant B can take in Stage 2.

4) Participant B cannot take more chips than Participant A has available after Stage 1. So, for example, imagine that both participants have 10 chips at the beginning of Stage 2 , because Participant A took 0 chips in Stage 1. In this case, $2 b$ cannot be greater than 10 , because that is all the chips Participant A has. This means that the most Participant B can take is 10 chips, in which case Participant B has to spend 5 chips to do so. This would leave Participant A with 0 chips and Participant B with 15 chips at the end of Stage 2.

\section{Guesses}

In addition to the above decisions, Participants A and B will guess what choices the participant with whom they are paired will make in the experiment. That is, Participant A will make a guess about how much Participant B will take in Stage $2(2 b)$ and Participant B will make a guess about how much Participant A will take in Stage $1(a)$. For making an accurate guess, Participants A and B can earn an additional CHF 4.

Participants $\mathrm{C}$, who do not make any other choices in the experiment, will make guesses about the decisions made by both Participants A and B. Participants C receive CHF 20, in addition to the CHF 10 show-up fee. For each accurate guess, Participant $\mathrm{C}$ can earn an additional CHF 4.

\section{Summary [paper only]}

Before we go over how you will enter your choices and guesses, we now summarize for each Participant, A, B or C, his or her choices and guesses.

Overview of decisions

- Participant A and Participant B each start with 10 chips. Each chip is worth CHF 2.00.

- In Stage 1, Participant A decides how many chips $(a)$ to take from Participant B.

- In Stage 2, Participant B decides how many chips (2b) to take from Participant A. For every $2 b$ chips Participant B takes from Participant A, Participant B has to spend $b$ chips. Participant B's ability to take chips from Participant A is therefore constrained by the number of chips Participant B is left with at the end of Stage 1, which depends on the decision of Participant A in Stage 1.

At the end of Stage 2, Participants A and B will end up with the following numbers of chips:

- Participant A: $10+a-2 b$

- Participant B: $10-a+2 b-b$

\section{Participant A}

Participant A will both choose an amount to take from his or her paired Participant B in Stage $1(a)$ and will guess how much his or her paired Participant B intends to take in Stage $2(2 b)$. For guessing accurately, Participant A can earn an additional CHF 4.

\section{Participant B}

Participant B will both indicate how much he or she would like to take from his or her paired Participant A in Stage $2(2 b)$ and will make a guess about how much his or her paired Participant A will take in Stage $1(a)$. For guessing accurately, Participant B can earn an additional CHF 4. 


\section{Participant C}

Participant $\mathrm{C}$ will not make any choices that affect other participants in the experiment. Instead, Participant $\mathrm{C}$ will start with CHF 20, in addition to the CHF 10 show-up fee. Participant $\mathrm{C}$ will make guesses about how much a randomly selected Participant A will take in Stage $1(a)$ and about how much a randomly selected Participant B intends to take in Stage $2(2 b)$. For each accurate guess, Participant $\mathrm{C}$ can earn an additional CHF 4.

All of the above choices and guesses will be made one time. After that, the experiment will conclude.

\section{Procedures for Decisions [paper only]}

\section{[Experimenter only:}

We are now going to provide you with instructions for the procedures you will use to make your decisions. Please click "Continue" on your screen to see an example Decision Screen. If your screen is blank, please move the mouse to activate it.]

\section{Entering choices [full decision screen]}

You each now see a Decision Screen. This screen presents the table on which all participants will enter their choices and guesses. This table displays all possible choices available to Participants A and B. Please take a moment to look at this table carefully, since your earnings will depend on understanding this table. You also have a copy of this table at your desk, to which you can refer at any point. We are now going to explain to you, step-by-step, how you enter your choices in that table.

Please click "Continue" to proceed to the next screen.

Participant A's decision [first two columns, corresponding to Participant A's decision]

On your screen, the first column, labeled "Participant A's decision in Stage 1," is now displayed prominently. This part of the screen presents all possible decisions (a) that Participant A can choose in Stage 1. Specifically, each row represents one possible decision available to Participant A.

Participant A can choose whether to take 0 chips, 2 chips, 4 chips, 6 chips, 8 chips or 10 chips from Participant $\mathrm{B}$, by selecting one of the boxes in the first column.

Using this part of the screen, Participant A will enter his or her choice of how much to take in Stage 1 (a). This will be the choice that counts for Participant A and will determine how many chips his or her paired Participant B has at the beginning of Stage 2.

Every possible choice, $a$, by Participant A in Stage 1, leaves Participant B with some amount of chips $(10-a)$ at the beginning of Stage 2 . Therefore, the second column shows the number of chips Participant B has available to spend in Stage 2.

On this part of the screen, Participants B and C will also enter their guesses of how much Participant A will take in Stage 1 by selecting one of the boxes in the first column.

Participant B will enter a guess of what his or her paired Participant A will choose. If Participant B's guess is the same as what his or her paired Participant A actually chooses, then Participant B will receive an additional payment of CHF 4.

Participant $\mathrm{C}$ will enter a guess of what a randomly selected Participant $\mathrm{A}$ will choose. If Participant C's guess is the same as what the randomly selected Participant A actually chooses, then Participant C will receive an additional payment of CHF 4.

All participants will make these choices and guesses by selecting one box in the first column. Note that the computer will only let you proceed if there is exactly one box selected in this column.

Once you are done looking at this part of the screen, click "Continue" to see how Participant B will enter his or her decision.

Participant B's decision [last two columns] 
The final column, labeled "Participant B's options in Stage 2," is now displayed prominently. This part of the screen presents a series of sub-tables, one for each possible amount that Participant B has available in Stage 2. The amount Participant B has available at the beginning of Stage 2 is displayed in the first column of the highlighted part of the table. The sub-table in each row describes all of the possible choices that Participant B can make, given that particular decision by Participant A in Stage 1. In each sub-table, you see all the possible amounts Participant B can take from Participant A (2b), based on how many chips Participant B has at the beginning of Stage 2. You also see the final payoffs, in chips, for both Participants A and B.

Using this part of the screen, Participant B will make a choice for each sub-table by indicating one possible action he wants to have implemented if that sub-table is the one that counts. That is, Participant B will enter a choice for every possible choice that Participant A might make. Participant B will make his or her choice without knowing how much Participant A took in Stage 1.The actual sub-table and choice that counts will be determined by what Participant A actually chooses.

Participant B's selected box of how much to take, $2 b$, in that respective sub-table will be implemented as Participant B's actual choice. Participant B should make each of these choices carefully, since any of them could be the one that actually counts, depending on what Participant A chooses.

On this part of the screen, Participants $\mathrm{A}$ and $\mathrm{C}$ will also enter their guesses of how much Participant $\mathrm{B}$ will take in each possible sub-table.

Participant A will enter guesses of what his or her paired Participant B will choose. Participant A will do so for each possible amount Participant B might have available at the beginning of Stage 2, by selecting one choice in each sub-table. At the end of the experiment, the computer will randomly select one sub-table. If Participant A's guess in that respective sub-table is the same as what his or her paired Participant B actually chooses in this sub-table, then Participant A will receive an additional payment of CHF 4.

Participant $\mathrm{C}$ will enter guesses of what a randomly selected Participant $\mathrm{B}$ will choose. Participant $\mathrm{C}$ will do so for each possible amount Participant B might have available at the beginning of Stage 2, by selecting one choice in each sub-table. At the end of the experiment, the computer will randomly select one sub-table. If Participant C's guess in that respective sub-table is the same number as what a randomly selected Participant $\mathrm{B}$ actually chooses in this sub-table, then Participant $\mathrm{C}$ will receive an additional payment of CHF 4 .

Please click "Continue" to see an example.

Example $[$ row corresponding to $\mathrm{a}=6]$

In this example, suppose Participant A chose to take 6 chips from Participant B in Stage $1(a=6)$. Then, the relevant part of the screen is the row that you now see highlighted.

Given that Participant A chose $a$ equal to 6 in Stage 1, Participant B has 4 chips at the beginning of Stage 2. This means that Participant B can spend either $0,1,2,3$ or 4 chips $(b)$ in order to take, respectively, $0,2,4,6$ or 8 chips $(2 b)$ from Participant A. Participant B can specify how many chips to take by selecting one box in that sub-table. For example, suppose Participant B wanted to take 8 chips from Participant A in Stage 2. Then, he or she would select the button that is at the far right of the sub-table, corresponding to $2 b=8$. In the same way, Participant B can choose any of the five options in this sub-table.

Please click "Continue" to return to the full screen. [full decision screen]

[Experimenter only:

Please look over the Decision Screen so that you are familiar with it, since this is how you will make all your decisions. [Pause for 10 seconds.]

So that you have the possibility to become more familiar with the Decision Screen, please click

"Continue" to see a Practice Decision Screen. ] 


\section{Instructions Practice Decision Table}

Using this screen, you can select hypothetical boxes for the choices of Participant A as well as for the choices of Participant B. You can select an amount that Participant A takes in Stage $1(a)$ by selecting one of the boxes in the first column. You can select the amounts that Participant B intends to take $(2 b)$, in each possible sub-table, by selecting one box in each sub-table of the final column.

Once you have entered one choice for Participant A and one choice in each sub-table for Participant B, you can see the consequences of these choices by clicking "Test." At the bottom right side of the screen, a box labeled "Outcome test" appears. In that box, you will see the implemented choice of Participant A ( $a)$ and the implemented choice of Participant B (2b). Moreover, you will see the final number of chips for each participant.

If you want to test another set of hypothetical choices, click "Clear" and a Decision Screen will appear in which you can enter other choices.

Once you are finished practicing with the table, click "End" and confirm your choice. Once all participants have finished practicing with the Decision Screen, you will answer a few questions to ensure that everyone understands the instructions.

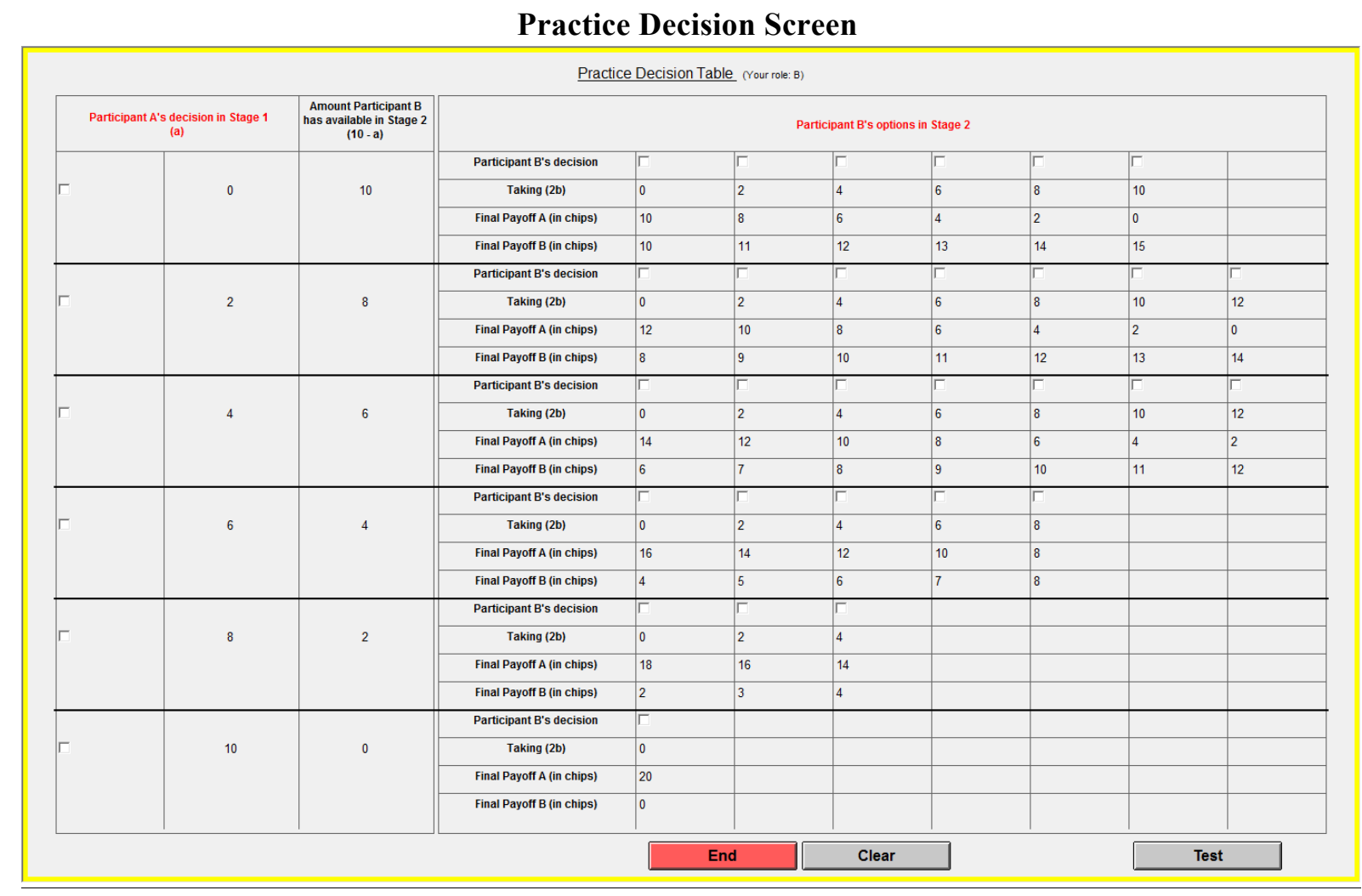

\section{Questions}

Please answer the following questions. While answering them, you may refer to the table in the paper instructions that shows you the possible combinations of choices by Participant A and Participant B and the resulting payoffs.

If you have a question, please raise your hand and wait for an experimenter to come to you.

For each question, you confirm your entries by clicking the "Ok" button. Then the next question appears. Once everyone has answered all questions correctly, you will see the Decision Screen on which you will enter your choices.

[Separated Screen (After control questions)] 
Everyone has now completed all the comprehension questions.

Once you are ready to proceed to the Decision Screen, please click the "Continue" button at the bottom. You will then enter your choices and guesses for the experiment.

[CONTINUE]

\section{Replication Di Tella, et al.}

Preparation: The lab is divided in two rooms, "room A" and "room B". Participants in room A and B cannot see (or hear) each other.

Procedure: Before participants enter the lab, the Pre-Lab Instructions (3.1) are read out in front of the lab. Then the 25 participants randomly draw a card with numbers $1-24,36$ on it. The participant with number 36 is the Monitor (instructions 1.2). Participants with number between 1 and 12 enter room A and participants with number between 13 and 24 enter room B. Then the welcome-audiofile (3.3.1) is played in both rooms. When the audiofile is finished, participants in both rooms have to do a task (instructions 3.3.2). Then the participants play the modified corruption game. Participants in room A are Allocator (instructions 3.3.3a / 3.3.3b) and participants in room B are Seller (instructions 3.3.3c). Finally, all participants (except Monitor) have to fill out a survey (3.3.4). The instructions 3.3.2, 3.3.3 and 3.3.4 closely follow the instructions of Di Tella, Perez-Truglia, Babino and Sigman (2015).

\subsection{Pre-Lab Instructions}

Welcome to today's session. Please note that the entire experiment is conducted in English. It is very important that you understand written and spoken instructions in English, so if you feel uncomfortable with this please inform me now.

Before beginning the experiment, we will randomly select one of you to fill the role of a monitor for the experiment. This person will assist with distributing forms and the payments at the end. We do this so that no one, not even the experimenters, will know the choices that other participants will make during the study. This monitor will receive a fixed payment for his or her participation and will not make any choices that affect how much money anyone makes.

Please select a card from the experimenter. If the card you selected contains the letter " 36 ", then you will be the monitor during this experiment. If you have this card, then please go inside the lab, where another experimenter will show you what to do.

In a moment, we will call the rest of you up, one person at a time. Once you are called, please take all of your belongings with you into the lab. The number on the card you drew corresponds to the desk at which you should sit in the lab.

As you enter the lab, you will be asked by the monitor to randomly draw an envelope from a box. Please make sure that the box from which you draw an envelope matches the number on your numbered card. Please do not open this envelope until we ask you to do so.

The envelope contains instructions and a randomly assigned ID-number. Note that since you will randomly choose an envelope, the ID-number is randomly assigned to you. Neither the experimenters nor other participants will know your ID-number. Throughout the study, please keep this ID-number private. It guarantees your anonymity throughout the experiment. At the end of the experiment, you will show this ID-number only to the monitor, in order to collect a sealed envelope with your payment. The monitor will have no way of knowing what choices you made. Thus, neither the experimenters, other participants, nor the monitor will be able to match your identity to any choices that you made.

\subsection{Instructions Monitor}

Thank you for participating in today's experiment.

You have been randomly selected to the role of the monitor. For acting in this role, you will get a fixed payment of CHF 25 at the end of the experiment. This means that your payment will not depend on the actions of other participants. Further, note that you will not be involved in any activity performed by the other participants. 
In today's study, the other participants will make decisions, which affect their own final payoffs as well as the payoffs of other participants. For making their decision, the experimenter assures them total anonymity. This means that the experimenter will never know which decisions a particular participant has made nor does he know how much money a participant has received for participating in the experiment. In order to assure this, we selected you as a monitor who will perform two tasks. Task 1 has to be done at the beginning of the experiment and Task 2 will be done at the end of the experiment.

We will provide you with the instructions for each task separately. So, we are now going to explain to you Task 1 only. After you have executed this task and all participants have started the experiment, we will give you a separate sheet for Task 2 .

\section{Task 1}

We are now going to explain to you Task 1, which you will perform in a moment:

1) As participants enter the laboratory, they will each have a green card that directs them to a particular seat. This card also corresponds to one of two boxes from which they should randomly draw an envelope. Please make sure that each participant draws one sealed envelope from the box that corresponds to his or her number.

All participants with number $1-12$ are guided to room A and should therefore draw an envelope from box A.

All participants with number $13-24$ are guided to room B and should therefore draw an envelope from box B.

Please raise your hand now to signal to the experimenter that you have finished reading the instructions for Task 1. If you have any questions about Task 1, please ask the experimenter now.

Once you have completed Task 1 and all the participants are seated, the experimenter will give you instructions for Task 2. 
Task 2

We now explain to you the nature of Task 2. At the end of the experiment, the experimenter will place envelopes on a table next to you at the exit. Each envelope has an ID-number on it. Each envelope contains the payment for each participant with the corresponding ID-number. We will call participants one-by-one to leave the room based on the green seating card.

Your task will be the following:

1. Ask each participant for his or her ID-number and verify that each participant takes the envelope that corresponds to that participant's ID-number, which will be on a yellow card. It is important that each participant take only the envelope corresponding to his or her ID-number.

2. Collect from each participant his or her green seating card and the instructions and gather them all at your table. Note that participants are only allowed to keep the yellow ID-number, if they want to.

During the experiment, you may sit at an empty desk and use your free time however you wish. If you have any questions about Task 2, please ask an experimenter to come to you. If you have finished reading the instructions for Task 2 and have understood everything, you may sit at an empty desk and use your free time however you wish.

\subsection{Instructions Allocator and Seller}

\subsubsection{Welcome (audiofile)}

Thank you for participating in today's experiment. Before making decisions in the study, please carefully read and sign the contract form on your desk first and put it aside on your table. If you do not agree with the contract form, please raise your hand high and wait for an experimenter to come to you. [pause]

Now, you need to complete a task. Therefore, please read the instructions for the task on the next page.

If you have any questions during the experiment, please raise your hand and wait for an experimenter to come to you. Please do not talk, exclaim, or try to communicate with other participants during the experiment. Participants intentionally violating the rules may be asked to leave the experiment and may not be paid anything beyond their participation payment.

Once you have completed the task, please raise your hand high and wait for an experimenter to come to you to check your answers. At this time, the experimenter will also collect your signed contract form. 
3.3.2 Instructions task (with solution)

Please find a particular sequence of $0 \mathrm{~s}$ and $1 \mathrm{~s}$ hidden in the following series of $0 \mathrm{~s}$ and $1 \mathrm{~s}$. When you find the sequence, draw a box around it. For example:

\section{Sample Task}

Sequence to be found: $\mathbf{1 0 1 1 1 0 1}$

101000000000010000010101000000100100101111000001001110101001011010011010 010000100001000110010100100001010111110110100100011100101111011000101101 001001010100100011011111001001010110110111101111111111110010100110101010 111001111001001001011110111110100001011111010000101111101000010000011111 1111001100000001000000001001111011111100001011101001101101010101010000 100000111100001010000001111110000111110000111110000111110000111110000111 110000111111111000011111000000000000000001111111111100000000010101010100

\section{Please complete the following 5 tasks.}

\section{Task 1 of 5}

Sequence to be found: $\mathbf{1 1 1 0 1 1 1}$ 101000000000010000010101000000100100101111000001001110101001011010011010 011000100001000110010100100001010111110110100100011100101111011000101101 001001010100100011011111001001010110110111101111111111110010100110101010 111001111001001011101010010111001111111011000101111101000011011011111010 110011000000100000000100111101101111000001011101000110110101011011010101 000001111000010100000011111100001111100001111100001111100001111100001111 100001111111110000111110000001101000001101100011111110010101000110000110

\section{Task 2 of 5}

Sequence to be found: $\mathbf{0 1 1 1 0 1 0}$

101000000000010000010101000000100100101111000001001100101001011010011010 011000100001000110010100100001010111110110100100011100101111011000101101 001001111100100011011111001001010110110111101111111111110010100111111110 111001111001001001011111111010000101111101000010111110100001000001111111 110011000000100000000100111101101111000001011101000110110111110000111000 001000001111000010111000011111100001111100001111100001111100000111110001 111100001111111110000111110000000000000000000011111111111100000000111101

\section{Task 3 of 5}

Sequence to be found: 1011011

101011001100010000010101000000100100101111000001001110101001011010011010 011000101101000110010100100001010111110110100100011100101111011000101101 001001010100100011011111001001010100110110101111111111110010100110101010 000001111000010100000011111100001111100001111100001111100001111100001111 111001111001001011101010010111011111111011000101111101000011010011111010 100001111101101111100001111100000011010011011000111111100101010001100110 110011000000100000000100111101001111000001011101000110110101111011010101

Task 4 of 5

Sequence to be found: $\mathbf{0 0 0 1 0 1 0}$ 
101000000000010000010101000000100100101111000001001110101001011010011010

100001111011110000110110000001101000001101100011111110010101000110000110

110011000000100000000100111101101111001001011101000110110101011011010101

000001101000011100000010011100001101100001111100001111100001001100001111

100001001111110000111110000001101000001101100011111110010101000110000110

001001010100100011011111001001010110110111101111111111110010100110101010

111001111001001011101010010111011111111011000101111101000011011011111010

\section{Task 5 of 5}

Sequence to be found: $\mathbf{1 0 1 0 0 1 1}$

101001000000010010011101001000100100101111000001001110101001011010010010 011000100001000110010100100001010111110100101001011100101111011000101101 001001010100100011011111001001001101111011110111111111110010110110101010 111001111010011110101010010111011111111011000101111101000011011011111010 110011000000100000000100111101101111000001011101000110110101011011010101 000001111000010100000011111100001111100001111100001111100001111100001111 100001111111110000111110000001101000001101100010101110010101000110000110

Once you complete the five tasks, please raise your hand high and wait for an experimenter to come to you to check your answers. After that, please wait until you receive further instructions.

After all Seller and Allocator are done with the task, they listen to the following message (audiofile):

Everyone has now completed the task. Please open the white envelope next to you. Inside the envelope, you will see a yellow paper with your ID-number for the experiment. Please first enter this ID-number on your screen and then confirm your entry with the "Ok" button.

Once you have confirmed your ID-number, please begin to read the instructions that are also in the white envelope.

\subsection{3a Instructions Allocator (Able=2)}

Note: The Allocator make their decision on the screen.

\section{Introduction}

You get a CHF 15 show-up fee that you receive for your participation. Additionally, you receive 10 tokens for completing the previous task.

The final amount you receive will be determined during the experiment and will depend on your decisions and the decisions of others. You will be paid privately, in cash, at the conclusion of the experiment based on your ID-number (yellow card). You will need this number at the end of the experiment to recover an envelope with your payment, so please keep this number with you and enter it on your screen now:

[Screen] Your ID-number:

Then press the "ok" button to confirm this number. At the end of the study, the experimenter will place each participant's earned money in an envelope, using only the ID-numbers. These envelopes will be placed on a table outside this room. You will be called up one-by-one, based on your seating card (green card), to collect the envelope with your ID-number. The randomly selected monitor, who does not participate in the experiment, will control that you take the right envelope.

Note that this procedure means that the experimenter does not know which participant had which IDnumber. Moreover, the monitor does not know how much money is inside each envelope or how much each participant has earned at the end of the experiment. 
Note further that the monitor is not in any way engaged in the experiment and is randomly selected only to guarantee you anonymity and for the purpose of paying you.

Note that this procedure is to assure that the experimenter will never know your identity. This means that the experimenter will not be able to associate any of your choices with your name; instead, the experimenter will only see choices linked to your ID-number.

The experiment is conducted in pairs. Your role is to be the "allocator", and you will be participating with another person, whose role is to be the "seller", and who is randomly chosen from the participants in another room. Each one will make a single decision, and then the payments will be distributed in accordance with some rules we will explain to you shortly.

In the contract you signed, we guarantee you that you are really participating with another person, and that your decision will therefore affect the payments to that participant (and yours).

The experiment is completely anonymous: neither the other participants, nor the researcher will be able to find out what your decision was. Nor will you be able to know the identity of the person with whom you are participating.

\section{Allocator: Your instructions}

You received 10 tokens on account of having completed the 5 tasks.

Your ID-number was randomly paired with another ID-number belonging to a "seller" with whom you will be making decisions. The "seller" also completed 5 tasks and received 10 tokens. Between the two of you, you have accumulated 20 tokens. You are going to decide how those 20 tokens are going to be distributed between you and the seller.

Out of the 20 tokens, you can choose how many you want to keep, and how many your partner will keep. The decision margin is chosen at random. This means that there are two types of allocator: those who can move up to 8 of each person's tokens, and those who can move up to 2 of each person's tokens.

You are able to move up to 2 tokens, which means that you can keep any number of tokens between 8 and 12 . Your partner will keep the remaining tokens (up to 20). Your options are presented in Table 1:

Table 1

\begin{tabular}{|c|c|}
\hline Tokens for the allocator & Tokens for the seller \\
\hline 12 & 8 \\
\hline 11 & 9 \\
\hline 10 & 10 \\
\hline 8 & 11 \\
\hline
\end{tabular}

Before you make your decision, we are going to provide you with the instructions received by the person who is randomly designated to participate with you (called the "seller"). What follows are the instructions your paired "seller" receives (remember that you are the allocator, not the seller). We provide you with the seller's instructions so that you see them and understand how the experiment works; as seen from your point of view and the person participating with you. 
NOTE: These are the seller's instructions, NOT your instructions.

\section{Seller's instructions}

You are the "seller." For the completed tasks, you received 10 tokens. Your ID-number was randomly paired with another ID-number belonging to an "allocator" with whom you are going to make some decisions. The allocator you are participating with did the same tasks and also earned 10 tokens. The allocator is going to distribute the 20 tokens accumulated by the two of you. He will decide how many tokens he is going to keep for himself and how many tokens you will get to keep.

We (the experimenters) are going to buy the tokens from you and from the allocator you are playing with. Your task is to negotiate the price of each token for both of you (you and the allocator). This means that the price you arrange for the tokens will be valid for both your tokens (the ones the allocator lets you keep) as well as the tokens the allocator is going to keep for herself. In other words, your decision will affect both of you. Either you can sell each token for CHF 1.80. Or you can also make a deal and sell them at CHF 0.60 each. If you do that, you will collect a premium of CHF 6 . To summarize, you (the seller) have to decide what the value of those 20 tokens will be at the end of the experiment. The options are:

Option A: Each token will be worth CHF 1.80.

Option B: Each token will be worth CHF 0.60, and as compensation you will receive CHF 6 only for yourself (plus the value of your tokens).

The allocator will not be able to know if you chose Option A or Option B until after the tokens have been distributed. Additionally, you (the seller) will not know how the allocator distributed the tokens until after you have chosen Option A or Option B. Remember that the experiment is completely anonymous; accordingly, the allocator does not know with whom he is participating. Likewise, you (the seller) do not know the identity of the allocator. When the allocator distributes the tokens, he has no way of knowing which option you are going to choose.

Finally, you need to know that there are two kinds of allocators: those who can move up to 8 of each person's tokens, and those who can move up to 2 of each person's tokens. What you do not know is what kind of allocator you get to play with. 
NOTE: These are your instructions again (Allocator)

\section{Examples}

Before you make your decision, let's look at an example:

If the seller chooses Option B (CHF 0.60 per token) and you choose to keep 12 tokens, you would collect: CHF $0.60 \times 12=$ CHF 7.20

And the seller would collect:

CHF $0.60 \times 8+$ CHF $6=$ CHF 10.80

On the other hand, if the seller chooses Option A (CHF 1.80 per token) and you choose to keep 10 tokens, you would collect:

CHF $1.80 \times 10=$ CHF 18

And the seller would collect:

CHF $1.80 \times 10=$ CHF 18

\section{Comprehension Questions}

Before continuing, we want to make sure the rules are clear, so we are going to ask you 5 questions. Note that if you answer any of the questions incorrectly, CHF 5 will be deducted from your final payoff.

After answering all the questions, confirm your entries by clicking the "Ok" button. Then, you will directly proceed to the decision screen.

\section{Allocator's instructions}

\section{Decisions}

We are now going to ask you to make your decision. On your screen you now see the exact same instructions as on this page.

Please provide all your answers on your screen in the respective boxes.

Before you make your decision about how to allocate the 20 tokens, we ask you some questions.

Bonus Questions: For an additional CHF 6. In your opinion, which of the following two options do you think your paired seller will choose? (select the respective box on your screen)

$\square \quad$ Option A: Each token will be worth CHF 1.80 .

$\square \quad$ Option B: Each token will be worth CHF 0.60 and CHF 6 for the seller only.

If your answer is correct, you will receive an additional CHF 6 as a prize.

Now is the time for you to make your decision on how to distribute the 20 tokens. Enter which of the options in Table 1 you choose:

\begin{tabular}{|l|l|}
\hline Tokens for You & Tokens for Your Partner \\
\hline & \\
\hline
\end{tabular}

Bonus Questions: For an additional CHF 6. Out of all the participants who were assigned to the role of the seller, we are going to calculate which percentage chose option B (CHF 0.60 per token plus CHF 6 for the seller only). In your opinion, what percentage chose option B?
$\square 0-10 \%$ of sellers chose Option B
$\square 10-20 \%$ of sellers chose Option B
$\square 20-30 \%$ of sellers chose Option B
$\square 30-40 \%$ of sellers chose Option B
$\square 40-50 \%$ of sellers chose Option B
$\square 50-60 \%$ of sellers chose Option B
$\square 60-70 \%$ of sellers chose Option B
$\square 70-80 \%$ of sellers chose Option B
$80-90 \%$ of sellers chose Option B
$90-100 \%$ of sellers chose Option B

If your answer is correct, you will receive an additional CHF 6 as a reward. 
The Able=2 Allocator anwer the following comprehension questions (on screen):

\section{Comprehension Questions}

1. If, when you distribute the tokens, you decide to keep 10 tokens for yourself and leave 10 tokens for the seller, and the seller chooses Option B (CHF 0.60 per token), how much will each one of you collect (in CHF):

Allocator (you): Seller:

2. If, when you distribute the tokens, you decide to keep 12 tokens for yourself and leave 8 tokens for the seller, and the seller chooses Option A (CHF 1.80 per token), how much will each one of you collect (in CHF):

Allocator (you): Seller:

3. Can the experimenter link your decision with your name?

$\square \quad$ Yes

$\square \quad$ No

4. Can the other participants find out if they are participating with you?

$\square \quad$ Yes

$\square \quad$ No

5. Even if your paired participant doesn't know who you are, does the seller know how the allocator distributed the 20 tokens before he chooses Option A or Option B?

$\square \quad$ Yes

$\square \quad$ No

\subsection{3b Instructions Allocator $($ Able $=8)$}

Note: The Allocator make their decision on the screen.

\section{Introduction}

You get a CHF 15 show-up fee that you receive for your participation. Additionally, you receive 10 tokens for completing the previous task.

The final amount you receive will be determined during the experiment and will depend on your decisions and the decisions of others. You will be paid privately, in cash, at the conclusion of the experiment based on your ID-number (yellow card). You will need this number at the end of the experiment to recover an envelope with your payment, so please keep this number with you and enter it on your screen now:

[Screen] Your ID-number:

Then press the "ok" button to confirm this number. At the end of the study, the experimenter will place each participant's earned money in an envelope, using only the ID-numbers. These envelopes will be placed on a table outside this room. You will be called up one-by-one, based on your seating card (green card), to collect the envelope with your ID-number. The randomly selected monitor, who does not participate in the experiment, will control that you take the right envelope.

Note that this procedure means that the experimenter does not know which participant had which IDnumber. Moreover, the monitor does not know how much money is inside each envelope or how much each participant has earned at the end of the experiment.

Note further that the monitor is not in any way engaged in the experiment and is randomly selected only to guarantee you anonymity and for the purpose of paying you.

Note that this procedure is to assure that the experimenter will never know your identity. This means that the experimenter will not be able to associate any of your choices with your name; instead, the experimenter will only see choices linked to your ID-number. 
The experiment is conducted in pairs. Your role is to be the "allocator", and you will be participating with another person, whose role is to be the "seller", and who is randomly chosen from the participants in another room. Each one will make a single decision, and then the payments will be distributed in accordance with some rules we will explain to you shortly.

In the contract you signed, we guarantee you that you are really participating with another person, and that your decision will therefore affect the payments to that participant (and yours).

The experiment is completely anonymous: neither the other participants, nor the researcher will be able to find out what your decision was. Nor will you be able to know the identity of the person with whom you are participating.

\section{Allocator: Your instructions}

You received 10 tokens on account of having completed the 5 tasks.

Your ID-number was randomly paired with another ID-number belonging to a "seller" with whom you will be making decisions. The "seller" also completed 5 tasks and received 10 tokens. Between the two of you, you have accumulated 20 tokens. You are going to decide how those 20 tokens are going to be distributed between you and the seller.

Out of the 20 tokens, you can choose how many you want to keep, and how many your partner will keep. The decision margin is chosen at random. This means that there are two types of allocator: those who can move up to 8 of each person's tokens, and those who can move up to 2 of each person's tokens.

You are able to move up to 8 tokens, which means that you can keep any number of tokens between 2 and 18. Your partner will keep the remaining tokens (up to 20). Your options are presented in Table 1:

Table 1

\begin{tabular}{|c|c|}
\hline Tokens for the allocator & Tokens for the seller \\
\hline 18 & 2 \\
\hline 17 & 3 \\
\hline 16 & 4 \\
\hline 15 & 5 \\
\hline 14 & 6 \\
\hline 13 & 7 \\
\hline 12 & 8 \\
\hline 11 & 9 \\
\hline 10 & 10 \\
\hline 9 & 11 \\
\hline 7 & 12 \\
\hline 6 & 13 \\
\hline 5 & 14 \\
\hline 4 & 15 \\
\hline 3 & 16 \\
\hline 2 & 17 \\
\hline
\end{tabular}

Before you make your decision, we are going to provide you with the instructions received by the person who is randomly designated to participate with you (called the "seller"). What follows are the instructions your paired "seller" receives (remember that you are the allocator, not the seller). We provide you with the seller's instructions so that you see them and understand how the experiment works; as seen from your point of view and the person participating with you. 
NOTE: These are the seller's instructions, NOT your instructions.

\section{Seller's instructions}

You are the "seller." For the completed tasks, you received 10 tokens. Your ID-number was randomly paired with another ID-number belonging to an "allocator" with whom you are going to make some decisions. The allocator you are participating with did the same tasks and also earned 10 tokens. The allocator is going to distribute the 20 tokens accumulated by the two of you. He will decide how many tokens he is going to keep for himself and how many tokens you will get to keep.

We (the experimenters) are going to buy the tokens from you and from the allocator you are playing with. Your task is to negotiate the price of each token for both of you (you and the allocator). This means that the price you arrange for the tokens will be valid for both your tokens (the ones the allocator lets you keep) as well as the tokens the allocator is going to keep for herself. In other words, your decision will affect both of you. Either you can sell each token for CHF 1.80. Or you can also make a deal and sell them at CHF 0.60 each. If you do that, you will collect a premium of CHF 6 . To summarize, you (the seller) have to decide what the value of those 20 tokens will be at the end of the experiment. The options are:

Option A: Each token will be worth CHF 1.80.

Option B: Each token will be worth CHF 0.60, and as compensation you will receive CHF 6 only for yourself (plus the value of your tokens).

The allocator will not be able to know if you chose Option A or Option B until after the tokens have been distributed. Additionally, you (the seller) will not know how the allocator distributed the tokens until after you have chosen Option A or Option B. Remember that the experiment is completely anonymous; accordingly, the allocator does not know with whom he is participating. Likewise, you (the seller) do not know the identity of the allocator. When the allocator distributes the tokens, he has no way of knowing which option you are going to choose.

Finally, you need to know that there are two kinds of allocators: those who can move up to 8 of each person's tokens, and those who can move up to 2 of each person's tokens. What you do not know is what kind of allocator you get to play with. 
NOTE: These are your instructions again (Allocator)

\section{Examples}

Before you make your decision, let's look at an example:

If the seller chooses Option B (CHF 0.60 per token) and you choose to keep 12 tokens, you would collect:

CHF $0.60 \times 12=$ CHF 7.20

And the seller would collect:

CHF $0.60 \times 8+$ CHF $6=$ CHF 10.80

On the other hand, if the seller chooses Option A (CHF 1.80 per token) and you choose to keep 10 tokens, you would collect:

CHF $1.80 \times 10=$ CHF 18

And the seller would collect:

CHF $1.80 \times 10=$ CHF 18

\section{Comprehension Questions}

Before continuing, we want to make sure the rules are clear, so we are going to ask you 5 questions. Note that if you answer any of the questions incorrectly, CHF 5 will be deducted from your final payoff.

After answering all the questions, confirm your entries by clicking the "Ok" button. Then, you will directly proceed to the decision screen.

\section{Allocator's instructions}

\section{Decisions}

We are now going to ask you to make your decision. On your screen you now see the exact same instructions as on this page.

\section{Please provide all your answers on your screen in the respective boxes.}

Before you make your decision about how to allocate the 20 tokens, we ask you some questions.

Bonus Questions: For an additional CHF 6. In your opinion, which of the following two options do you think your paired seller will choose? (select the respective box on your screen)

$\square \quad$ Option A: Each token will be worth CHF 1.80.

$\square \quad$ Option B: Each token will be worth CHF 0.60 and CHF 6 for the seller only.

If your answer is correct, you will receive an additional CHF 6 as a prize.

Now is the time for you to make your decision on how to distribute the 20 tokens. Enter which of the options in Table 1 you choose:

\begin{tabular}{|l|l|}
\hline Tokens for You & Tokens for Your Partner \\
\hline & \\
\hline
\end{tabular}

Bonus Questions: For an additional CHF 6. Out of all the participants who were assigned to the role of the seller, we are going to calculate which percentage chose option B (CHF 0.60 per token plus CHF 6 for the seller only). In your opinion, what percentage chose option B?

$\square 0-10 \%$ of sellers chose Option B

$\square 10-20 \%$ of sellers chose Option B

$\square 20-30 \%$ of sellers chose Option B

$\square 30-40 \%$ of sellers chose Option B

$\square 40-50 \%$ of sellers chose Option B 
$\square 50-60 \%$ of sellers chose Option B

$\square 60-70 \%$ of sellers chose Option B

$\square 70-80 \%$ of sellers chose Option B

$\square 80-90 \%$ of sellers chose Option B

$\square 90-100 \%$ of sellers chose Option B

If your answer is correct, you will receive an additional CHF 6 as a reward.

The Able $=8$ Allocator anwer the following comprehension questions (on screen):

\section{Comprehension Questions}

1. If, when you distribute the tokens, you decide to keep 10 tokens for yourself and leave 10 tokens for the seller, and the seller chooses Option B (CHF 0.60 per token), how much will each one of you collect (in CHF):

Allocator (you): Seller:

2. If, when you distribute the tokens, you decide to keep 12 tokens for yourself and leave 8 tokens for the seller, and the seller chooses Option A (CHF 1.80 per token), how much will each one of you collect (in CHF):

Allocator (you): Seller:

3. Can the experimenter link your decision with your name?

$\square \quad$ Yes

$\square \quad$ No

4. Can the other participants find out if they are participating with you?

$\square \quad$ Yes

$\square \quad$ No

5. Even if your paired participant doesn't know who you are, does the seller know how the allocator distributed the 20 tokens before he chooses Option A or Option B?

$\square \quad$ Yes

$\square$ No

\subsection{3c Instructions Seller}

Note: The Seller make their decision on the screen.

\section{Introduction}

You get a CHF 15 show-up fee that you receive for your participation. Additionally, you receive 10 tokens for completing the previous task.

The final amount you receive will be determined during the experiment and will depend on your decisions and the decisions of others. You will be paid privately, in cash, at the conclusion of the experiment based on your ID-number (yellow card). You will need this number at the end of the experiment to recover an envelope with your payment, so please keep this number with you and enter it on your screen now:

[Screen] Your ID-number: 
Then press the "ok" button to confirm this number. At the end of the study, the experimenter will place each participant's earned money in an envelope, using only the ID-numbers. These envelopes will be placed on a table outside this room. You will be called up one-by-one, based on your seating card (green card), to collect the envelope with your ID-number. The randomly selected monitor, who does not participate in the experiment, will control that you take the right envelope.

Note that this procedure means that the experimenter does not know which participant had which IDnumber. Moreover, the monitor does not know how much money is inside each envelope or how much each participant has earned at the end of the experiment.

Note further that the monitor is not in any way engaged in the experiment and is randomly selected only to guarantee you anonymity and for the purpose of paying you.

Note that this procedure is to assure that the experimenter will never know your identity. This means that the experimenter will not be able to associate any of your choices with your name; instead, the experimenter will only see choices linked to your ID-number.

The experiment is conducted in pairs. Your role is to be the "seller", and you will be participating with another person, whose role is to be the "allocator", and who is randomly chosen from the participants in another room. Each one will make a single decision, and then the payments will be distributed in accordance with some rules we will explain to you shortly.

In the contract you signed, we guarantee you that you are really participating with another person, and that your decision will therefore affect the payments to that participant (and yours).

The experiment is completely anonymous: neither the other participants, nor the researcher will be able to find out what your decision was. Nor will you be able to know the identity of the person with whom you are participating.

\section{Instructions}

You are the "seller." For the completed tasks, you received 10 tokens. Your ID-number was randomly paired with another ID-number belonging to an "allocator" with whom you are going to make some decisions. The allocator you are participating with did the same tasks and also earned 10 tokens. The allocator is going to distribute the 20 tokens accumulated by the two of you. He will decide how many tokens he is going to keep for himself and how many tokens you will get to keep.

We (the experimenters) are going to buy the tokens from you and from the allocator you are playing with. Your task is to negotiate the price of each token for both of you (you and the allocator). This means that the price you arrange for the tokens will be valid for both your tokens (the ones the allocator lets you keep) as well as the tokens the allocator is going to keep for herself. In other words, your decision will affect both of you. Either you can sell each token for CHF 1.80. Or you can also make a deal and sell them at CHF 0.60 each. If you do that, you will collect a premium of CHF 6 . To summarize, you (the seller) have to decide what the value of those 20 tokens will be at the end of the experiment. The options are:

Option A: Each token will be worth CHF 1.80.

Option B: Each token will be worth CHF 0.60, and as compensation you will receive CHF 6 only for yourself (plus the value of your tokens).

The allocator will not be able to know if you chose Option A or Option B until after the tokens have been distributed. Additionally, you (the seller) will not know how the allocator distributed the tokens until after you have chosen Option A or Option B. Remember that the experiment is completely anonymous; accordingly, the allocator does not know with whom he is participating. Likewise, you (the seller) do not know the identity of the allocator. When the allocator distributes the tokens, he has no way of knowing which option you are going to choose.

Finally, you need to know that there are two kinds of allocators: those who can move up to 8 of each person's tokens, and those who can move up to 2 of each person's tokens. What you do not know is what kind of allocator you get to play with.

\section{Comprehension Questions}

Before continuing, we want to make sure the rules are clear, so we are going to ask you 4 questions. Note that if you answer any of the questions incorrectly, CHF 5 will be deducted from your final payoff. 
After answering all the questions, confirm your entries by clicking the "Ok" button. Then, you will directly proceed to the decision screen.

\section{Decisions}

We are now going to ask you to make your decision. On your screen you now see the exact same instructions as on this page.

\section{Please provide all your answers on your screen in the respective boxes.}

Please choose which option you want:

$\square \quad$ Option A: Each token will be worth CHF 1.80.

$\square \quad$ Option B: Each token will be worth CHF 0.60 and CHF 6 just for you.

The Seller anwer the following comprehension questions (on screen):

\section{Comprehension Questions}

1. If the allocator decides to keep 10 tokens and leave you 10 tokens, and you choose option $B$ (CHF 0.60 per token), how much will each one of you collect (in CHF):

Seller (you): Allocator:

2. If the allocator decides to keep 18 tokens for himself and leave 2 tokens for you, and at the same time you arrange for the high price of CHF 1.80 per token (Option A), how much will each one of you collect (in $\mathrm{CHF}$ ):

Seller (you): Allocator:

3. Can the other player (or the experimenter) find out who you are, or is your identity completely anonymous (the experimenter knows only the ID-number to whom the payments must be made)?

$\square \quad$ The other player (or the experimenters) know who decided what

$\square \quad$ The decision is completely anonymous

4. Even if your paired participant doesn't know who you are, does the seller know how the allocator distributed the 20 tokens before he chooses Option A or Option B?

$\square$ Yes

$\square \quad$ No

\subsubsection{Survey}

All Allocator and Seller answer the following Survey in zTree.

\section{Please answer the following questions:}

1. Did you understand the rules of the experiment?

$\square \quad$ I fully understood them

口 I almost fully understood them

I only partially understood them

$\square \quad$ I did not understand them

2. Would you like to be called for a future experiment?

$\square \quad$ Yes 
$\square \quad$ No

3. How old are you?

4. What is your gender?

$\square \quad$ Female

$\square \quad$ Male

5. As compared to the families of the other students in your university, do you think your family is;

$\square \quad$ Much poorer than the average

$\square \quad$ Poorer than the average

$\square \quad$ As the average

$\square$ Richer than the average

$\square \quad$ Much richer than the average

6. There are currently people who want more income redistribution, and who reject the criticisms of people who say that would be a bad thing (for example, because it would lead to inefficiency in production, inflation, or other problems). Do you agree that the government should redistribute more? I Agree that ...

口 redistribution should be increased a lot

$\square \quad$ redistribution should be increased a little

$\square \quad$ current redistribution levels should be maintained

$\square \quad$ redistribution levels should be decreased a little

$\square \quad$ current redistribution levels should be decreased a lot

7. What is your field of study (major)?

7. UZH, Faculty of Theology

8. UZH, Faculty of Law

9. UZH, Faculty of Economics, Business Administration, Information Technology

10. UZH, Faculty of Medicine

11. UZH; Vetsuisse-Faculty

12. UZH; Faculty of Arts

13. UZH, Faculty of Science

14. ETH, Department of Architecture and Civil Engineering

15. ETH, Department of Engineering Sciences

16. ETH, Department of Natural Sciences and Mathematics

17. ETH, Department of System-oriented Natural Sciences

18. ETH, Department of Management, Technology and Economics

19. Other

When they are done with the Survey, subjects see the following waiting screen:

You have now finished the experiment. We will shortly begin to call participants one-by-one to come to the cashpoint outside the room to collect their payments. Please note that we will call you based on your seating number (green card). Once it is your turn to leave the room please take all your personal belongings with you, especially the ID-number (yellow card), as you will be paid based on this ID-number by the monitor. 


\section{Neutral Treatment}

After the subjects enter the lab, the welcome-audiofile (4.1) is played. Then they complete a task (instructions 4.2). Next, they receive the instructions of the $A b l e=2$ or Able $=8$ Allocators and then have to guess what Sellers in a previous study did (instructions 4.3.1/4.3.2). Finally, they complete a survey (4.4).

\subsection{Welcome (audiofile)}

Thank you for participating in today's experiment. Before making decisions in the study, please carefully read and sign the contract form on your desk first and put it aside on your table. If you do not agree with the contract form, please raise your hand high and wait for an experimenter to come to you. [pause]

Now, you need to complete a task. Therefore, please read the instructions for the task on the next page.

If you have any questions during the experiment, please raise your hand and wait for an experimenter to come to you. Please do not talk, exclaim, or try to communicate with other participants during the experiment. Participants intentionally violating the rules may be asked to leave the experiment and may not be paid anything beyond their participation payment.

Once you have completed the task, please raise your hand high and wait for an experimenter to come to you to check your answers. At this time, the experimenter will also collect your signed contract form.

\subsection{Instructions task (with solution)}

Please find a particular sequence of $0 \mathrm{~s}$ and $1 \mathrm{~s}$ hidden in the following series of $0 \mathrm{~s}$ and $1 \mathrm{~s}$. When you find the sequence, draw a box around it. For example:

\section{Sample Task}

Sequence to be found: 1011101

101000000000010000010101000000100100101111000001001110101001011010011010 010000100001000110010100100001010111110110100100011100101111011000101101 001001010100100011011111001001010110110111101111111111110010100110101010 111001111001001001011110111110100001011111010000101111101000010000011111 1111001100000001000000001001111011111100001011101001101101010101010000 100000111100001010000001111110000111110000111110000111110000111110000111 110000111111111000011111000000000000000001111111111100000000010101010100

\section{Please complete the following 5 tasks.}

\section{Task 1 of 5}

Sequence to be found: $\mathbf{1 1 1 0 1 1 1}$

101000000000010000010101000000100100101111000001001110101001011010011010 011000100001000110010100100001010111110110100100011100101111011000101101 001001010100100011011111001001010110110111101111111111110010100110101010 111001111001001011101010010111001111111011000101111101000011011011111010 110011000000100000000100111101101111000001011101000110110101011011010101 000001111000010100000011111100001111100001111100001111100001111100001111 100001111111110000111110000001101000001101100011111110010101000110000110

\section{Task 2 of 5}

Sequence to be found: 0111010 
101000000000010000010101000000100100101111000001001100101001011010011010 011000100001000110010100100001010111110110100100011100101111011000101101 001001111100100011011111001001010110110111101111111111110010100111111110 111001111001001001011111111010000101111101000010111110100001000001111111 110011000000100000000100111101101111000001011101000110110111110000111000 001000001111000010111000011111100001111100001111100001111100000111110001 111100001111111110000111110000000000000000000011111111111100000000111101

\section{Task 3 of 5}

Sequence to be found: 1011011

101011001100010000010101000000100100101111000001001110101001011010011010 011000101101000110010100100001010111110110100100011100101111011000101101 001001010100100011011111001001010100110110101111111111110010100110101010 000001111000010100000011111100001111100001111100001111100001111100001111 111001111001001011101010010111011111111011000101111101000011010011111010 100001111101101111100001111100000011010011011000111111100101010001100110 110011000000100000000100111101001111000001011101000110110101111011010101

\section{Task 4 of 5}

Sequence to be found: $\mathbf{0 0 0 1 0 1 0}$

101000000000010000010101000000100100101111000001001110101001011010011010 100001111011110000110110000001101000001101100011111110010101000110000110 110011000000100000000100111101101111001001011101000110110101011011010101 000001101000011100000010011100001101100001111100001111100001001100001111 100001001111110000111110000001101000001101100011111110010101000110000110 001001010100100011011111001001010110110111101111111111110010100110101010 111001111001001011101010010111011111111011000101111101000011011011111010

\section{Task 5 of 5}

Sequence to be found: 1010011

101001000000010010011101001000100100101111000001001110101001011010010010 011000100001000110010100100001010111110100101001011100101111011000101101 001001010100100011011111001001001101111011110111111111110010110110101010 111001111010011110101010010111011111111011000101111101000011011011111010 110011000000100000000100111101101111000001011101000110110101011011010101 000001111000010100000011111100001111100001111100001111100001111100001111 100001111111110000111110000001101000001101100010101110010101000110000110

Once you complete the five tasks, please raise your hand high and wait for an experimenter to come to you to check your answers. After that, please wait until you receive further instructions. 
After all Participants are done with the task, they listen to the following message (audiofile): Everyone has now completed the task. Please open the white envelope next to you. Inside the envelope, you will find the instructions for the rest of this experiment. Please begin now to read the instructions.

\subsection{Instructions belief elicitation}

\subsubsection{Instructions for Neutral Participants shown perspective of Able $=8$ Allocator}

\section{Your Instructions}

Thank you for participating in today's experiment. For your participation and completing the task, you will be paid a fixed payment of CHF 15 . You will have the opportunity to earn some more money by preforming a second task, which we will describe now.

On the following (pink) pages, you will read the instructions provided to a participant in a previous experiment. These instructions describe an interactive task in which two participants, an "Allocator" and a "Seller", both made decisions that affected one another.

You receive the instructions so that you have specific and complete information about the entire experiment and see the exact instructions provided to Allocators. Furthermore, since the Allocators were also provided with the instructions given to Sellers, you will also read the instructions given to Sellers.

Note that these instructions do not describe any choices that you or others will make during this experiment. They simply describe an experiment that took place previously.

After you read the instructions provided to an Allocator (pink pages), you will be asked to provide guesses about something that happened in the previous experiment. For the accuracy of your guesses, you can earn up to CHF 12. For this reason, you should pay close attention when reading the following instructions.

Note that these guesses are the only choice you will make in this experiment. After making your guess, the experiment will conclude and you will be paid privately.

Three additional comments on the procedure of the previous experiment:

- The two participants did not know each other, were seated in two different sections of this laboratory (with a dividing wall between them), and interacted only through computers.

- All participants in the experiment were paid privately, by a subject who had been randomly selected to serve as a "monitor" and who could not match anyone with the choices they had made. Therefore, both Allocators and Sellers made choices in a manner that no one, not even the experimenter, could match them up to their specific decisions.

- Before the interactive task started, the "Allocator" and the "Seller" both had to do the same task you did before (find a sequence of $0 \mathrm{~s}$ and 1s) and received a payment of 10 tokens each. These are the tokens referred to in the instructions provided to an Allocator (pink pages).

Please read now the instructions provided to an Allocator on the following (pink) pages. 


\section{NOTE: These are the Allocator's instructions, NOT your instructions.}

\section{Introduction}

You get a CHF 15 show-up fee that you receive for your participation. Additionally, you receive 10 tokens for completing the previous task.

The final amount you receive will be determined during the experiment and will depend on your decisions and the decisions of others. You will be paid privately, in cash, at the conclusion of the experiment based on your ID-number (yellow card). You will need this number at the end of the experiment to recover an envelope with your payment, so please keep this number with you and enter it on your screen now:

[Screen] Your ID-number:

Then press the "ok" button to confirm this number. At the end of the study, the experimenter will place each participant's earned money in an envelope, using only the ID-numbers. These envelopes will be placed on a table outside this room. You will be called up one-by-one, based on your seating card (green card), to collect the envelope with your ID-number. The randomly selected monitor, who does not participate in the experiment, will control that you take the right envelope.

Note that this procedure means that the experimenter does not know which participant had which IDnumber. Moreover, the monitor does not know how much money is inside each envelope or how much each participant has earned at the end of the experiment.

Note further that the monitor is not in any way engaged in the experiment and is randomly selected only to guarantee you anonymity and for the purpose of paying you.

Note that this procedure is to assure that the experimenter will never know your identity. This means that the experimenter will not be able to associate any of your choices with your name; instead, the experimenter will only see choices linked to your ID-number.

The experiment is conducted in pairs. Your role is to be the "allocator", and you will be participating with another person, whose role is to be the "seller", and who is randomly chosen from the participants in another room. Each one will make a single decision, and then the payments will be distributed in accordance with some rules we will explain to you shortly.

In the contract you signed, we guarantee you that you are really participating with another person, and that your decision will therefore affect the payments to that participant (and yours).

The experiment is completely anonymous: neither the other participants, nor the researcher will be able to find out what your decision was. Nor will you be able to know the identity of the person with whom you are participating. 


\section{NOTE: These are the Allocator's instructions, NOT your instructions.}

\section{Allocator: Your instructions}

You received 10 tokens on account of having completed the 5 tasks.

Your ID-number was randomly paired with another ID-number belonging to a "seller" with whom you will be making decisions. The "seller" also completed 5 tasks and received 10 tokens. Between the two of you, you have accumulated 20 tokens. You are going to decide how those 20 tokens are going to be distributed between you and the seller.

Out of the 20 tokens, you can choose how many you want to keep, and how many your partner will keep. The decision margin is chosen at random. This means that there are two types of allocator: those who can move up to 8 of each person's tokens, and those who can move up to 2 of each person's tokens.

You are able to move up to 8 tokens, which means that you can keep any number of tokens between 2 and 18. Your partner will keep the remaining tokens (up to 20). Your options are presented in Table 1: Table 1

\begin{tabular}{|c|c|}
\hline Tokens for the allocator & Tokens for the seller \\
\hline 18 & 2 \\
\hline 17 & 3 \\
\hline 16 & 4 \\
\hline 15 & 5 \\
\hline 14 & 6 \\
\hline 13 & 7 \\
\hline 12 & 8 \\
\hline 11 & 9 \\
\hline 10 & 10 \\
\hline 9 & 11 \\
\hline 8 & 12 \\
\hline 7 & 13 \\
\hline 6 & 14 \\
\hline 5 & 15 \\
\hline 4 & 16 \\
\hline 3 & 17 \\
\hline 2 & 18 \\
\hline
\end{tabular}

Before you make your decision, we are going to provide you with the instructions received by the person who is randomly designated to participate with you (called the "seller"). What follows are the instructions your paired "seller" receives (remember that you are the allocator, not the seller). We provide you with the seller's instructions so that you see them and understand how the experiment works; as seen from your point of view and the person participating with you. 


\section{Seller's instructions}

You are the "seller." For the completed tasks, you received 10 tokens. Your ID-number was randomly paired with another ID-number belonging to an "allocator" with whom you are going to make some decisions. The allocator you are participating with did the same tasks and also earned 10 tokens.

The allocator is going to distribute the 20 tokens accumulated by the two of you. He will decide how many tokens he is going to keep for himself and how many tokens you will get to keep.

We (the experimenters) are going to buy the tokens from you and from the allocator you are playing with. Your task is to negotiate the price of each token for both of you (you and the allocator). This means that the price you arrange for the tokens will be valid for both your tokens (the ones the allocator lets you keep) as well as the tokens the allocator is going to keep for herself. In other words, your decision will affect both of you. Either you can sell each token for CHF 1.80. Or you can also make a deal and sell them at CHF 0.60 each. If you do that, you will collect a premium of CHF 6 . To summarize, you (the seller) have to decide what the value of those 20 tokens will be at the end of the experiment. The options are:

Option A: Each token will be worth CHF 1.80.

Option B: Each token will be worth CHF 0.60, and as compensation you will receive CHF 6 only for yourself (plus the value of your tokens).

The allocator will not be able to know if you chose Option A or Option B until after the tokens have been distributed. Additionally, you (the seller) will not know how the allocator distributed the tokens until after you have chosen Option A or Option B. Remember that the experiment is completely anonymous; accordingly, the allocator does not know with whom he is participating. Likewise, you (the seller) do not know the identity of the allocator. When the allocator distributes the tokens, he has no way of knowing which option you are going to choose.

Finally, you need to know that there are two kinds of allocators: those who can move up to 8 of each person's tokens, and those who can move up to 2 of each person's tokens. What you do not know is what kind of allocator you get to play with. 


\section{NOTE: These are the Allocator's instructions, NOT your instructions.}

\section{Examples}

Before you make your decision, let's look at an example:

If the seller chooses Option B (CHF 0.60 per token) and you choose to keep 12 tokens, you would collect:

CHF $0.60 \times 12=$ CHF 7.20

And the seller would collect:

CHF $0.60 \times 8+$ CHF $6=$ CHF 10.80

On the other hand, if the seller chooses Option A (CHF 1.80 per token) and you choose to keep 10 tokens, you would collect:

$$
\text { CHF } 1.80 \times 10=\text { CHF } 18
$$

And the seller would collect:

CHF $1.80 \times 10=$ CHF 18

\section{Comprehension Questions [Allocator - On screen]}

Before continuing, we want to make sure the rules are clear, so we are going to ask you 5 questions. Note that if you answer any of the questions incorrectly, CHF 5 will be deducted from your final payoff.

After answering all the questions, confirm your entries by clicking the "Ok" button. Then, you will directly proceed to the decision screen. 
Before continuing, we want to make sure the rules of the previous experiment for which you just read the instructions are clear, so we are going to ask you 5 questions. Note that if you answer any of the questions incorrectly, CHF 5 will be deducted from your final payoff.

After answering all the questions, confirm your entries by clicking the "Ok" button. Then, you will directly proceed to the decision screen.

We are now going to ask you to make your guesses. On your screen, you now see the exact same instructions as on this page.

Please provide all your answers on your screen in the respective boxes.

\section{Guess 1}

For an additional CHF 6: In your opinion, which of the following two options did a randomly chosen seller in the previous experiment choose? (select the respective box on your screen)

$\square \quad$ Option A: Each token will be worth CHF 1.80.

$\square$ Option B: Each token will be worth CHF 0.60 and CHF 6 for the seller only.

We will compare you answer to the choice made by a randomly chosen seller. If your answer is correct, you will receive an additional CHF 6 as a prize.

\section{Guess 2}

For an additional CHF 6: Out of all the participants who were assigned to the role of the seller in a previous session of the experiment, we calculated which percentage chose option B (CHF 0.60 per token plus CHF 6 for the seller only). In your opinion, what was the percentage of sellers who chose option B?

$\square 0-10 \%$ of sellers chose Option B

$\square 10-20 \%$ of sellers chose Option B

$\square 20-30 \%$ of sellers chose Option B

$\square 30-40 \%$ of sellers chose Option B

$\square 40-50 \%$ of sellers chose Option B

$\square 50-60 \%$ of sellers chose Option B

$\square 60-70 \%$ of sellers chose Option B

$\square 70-80 \%$ of sellers chose Option B

$\square 80-90 \%$ of sellers chose Option B

$\square 90-100 \%$ of sellers chose Option B

If your answer is correct, you will receive an additional CHF 6 as a reward. 
The participants anwer the following comprehension questions (on screen):

\section{Comprehension Questions}

1. If, when distributing the tokens, an allocator decides to keep 10 tokens for himself and leave 10 tokens for his paired seller, and the seller chooses Option B (CHF 0.60 per token), how much will each one of them collect (in CHF):

Allocator: Seller:

2. If, when distributing the tokens, an allocator decides to keep 12 tokens for himself and leave 8 tokens for his paired seller, and the seller chooses Option A (CHF 1.80 per token), how much will each one of them collect (in CHF):

Allocator: Seller:

3. Can the experimenter link the decisions made by allocators or sellers in the previous experiment with their names?

$\square \quad$ Yes

$\square \quad$ No

4. Can participants in the previous experiment find out who they are paired with?

$\square$ Yes

$\square \quad$ No

5. Did the seller in the previous experiment know how his allocator distributed the 20 tokens before he chose Option A or Option B?

$\square \quad$ Yes

口 No 


\section{Your Instructions}

Thank you for participating in today's experiment. For your participation and completing the task, you will be paid a fixed payment of CHF 15 . You will have the opportunity to earn some more money by preforming a second task, which we will describe now.

On the following (pink) pages, you will read the instructions provided to a participant in a previous experiment. These instructions describe an interactive task in which two participants, an "Allocator" and a "Seller", both made decisions that affected one another.

You receive the instructions so that you have specific and complete information about the entire experiment and see the exact instructions provided to Allocators. Furthermore, since the Allocators were also provided with the instructions given to Sellers, you will also read the instructions given to Sellers.

Note that these instructions do not describe any choices that you or others will make during this experiment. They simply describe an experiment that took place previously.

After you read the instructions provided to an Allocator (pink pages), you will be asked to provide guesses about something that happened in the previous experiment. For the accuracy of your guesses, you can earn up to CHF 12. For this reason, you should pay close attention when reading the following instructions.

Note that these guesses are the only choice you will make in this experiment. After making your guess, the experiment will conclude and you will be paid privately.

Three additional comments on the procedure of the previous experiment:

- The two participants did not know each other, were seated in two different sections of this laboratory (with a dividing wall between them), and interacted only through computers.

- All participants in the experiment were paid privately, by a subject who had been randomly selected to serve as a "monitor" and who could not match anyone with the choices they had made. Therefore, both Allocators and Sellers made choices in a manner that no one, not even the experimenter, could match them up to their specific decisions.

- Before the interactive task started, the "Allocator" and the "Seller" both had to do the same task you did before (find a sequence of $0 \mathrm{~s}$ and $1 \mathrm{~s}$ ) and received a payment of 10 tokens each. These are the tokens referred to in the instructions provided to an Allocator (pink pages).

Please read now the instructions provided to an Allocator on the following (pink) pages. 


\section{NOTE: These are the Allocator's instructions, NOT your instructions.}

\section{Introduction}

You get a CHF 15 show-up fee that you receive for your participation. Additionally, you receive 10 tokens for completing the previous task.

The final amount you receive will be determined during the experiment and will depend on your decisions and the decisions of others. You will be paid privately, in cash, at the conclusion of the experiment based on your ID-number (yellow card). You will need this number at the end of the experiment to recover an envelope with your payment, so please keep this number with you and enter it on your screen now:

[Screen] Your ID-number:

Then press the "ok" button to confirm this number. At the end of the study, the experimenter will place each participant's earned money in an envelope, using only the ID-numbers. These envelopes will be placed on a table outside this room. You will be called up one-by-one, based on your seating card (green card), to collect the envelope with your ID-number. The randomly selected monitor, who does not participate in the experiment, will control that you take the right envelope.

Note that this procedure means that the experimenter does not know which participant had which IDnumber. Moreover, the monitor does not know how much money is inside each envelope or how much each participant has earned at the end of the experiment.

Note further that the monitor is not in any way engaged in the experiment and is randomly selected only to guarantee you anonymity and for the purpose of paying you.

Note that this procedure is to assure that the experimenter will never know your identity. This means that the experimenter will not be able to associate any of your choices with your name; instead, the experimenter will only see choices linked to your ID-number.

The experiment is conducted in pairs. Your role is to be the "allocator", and you will be participating with another person, whose role is to be the "seller", and who is randomly chosen from the participants in another room. Each one will make a single decision, and then the payments will be distributed in accordance with some rules we will explain to you shortly.

In the contract you signed, we guarantee you that you are really participating with another person, and that your decision will therefore affect the payments to that participant (and yours).

The experiment is completely anonymous: neither the other participants, nor the researcher will be able to find out what your decision was. Nor will you be able to know the identity of the person with whom you are participating. 


\section{NOTE: These are the Allocator's instructions, NOT your instructions.}

\section{Allocator: Your instructions}

You received 10 tokens on account of having completed the 5 tasks.

Your ID-number was randomly paired with another ID-number belonging to a "seller" with whom you will be making decisions. The "seller" also completed 5 tasks and received 10 tokens. Between the two of you, you have accumulated 20 tokens. You are going to decide how those 20 tokens are going to be distributed between you and the seller.

Out of the 20 tokens, you can choose how many you want to keep, and how many your partner will keep. The decision margin is chosen at random. This means that there are two types of allocator: those who can move up to 8 of each person's tokens, and those who can move up to 2 of each person's tokens.

You are able to move up to 2 tokens, which means that you can keep any number of tokens between 8 and 12. Your partner will keep the remaining tokens (up to 20). Your options are presented in Table 1: Table 1

\begin{tabular}{|c|c|}
\hline Tokens for the allocator & Tokens for the seller \\
\hline 12 & 8 \\
\hline 11 & 9 \\
\hline 10 & 10 \\
\hline 8 & 11 \\
\hline
\end{tabular}

Before you make your decision, we are going to provide you with the instructions received by the person who is randomly designated to participate with you (called the "seller"). What follows are the instructions your paired "seller" receives (remember that you are the allocator, not the seller). We provide you with the seller's instructions so that you see them and understand how the experiment works; as seen from your point of view and the person participating with you. 


\section{Seller's instructions}

You are the "seller." For the completed tasks, you received 10 tokens. Your ID-number was randomly paired with another ID-number belonging to an "allocator" with whom you are going to make some decisions. The allocator you are participating with did the same tasks and also earned 10 tokens.

The allocator is going to distribute the 20 tokens accumulated by the two of you. He will decide how many tokens he is going to keep for himself and how many tokens you will get to keep.

We (the experimenters) are going to buy the tokens from you and from the allocator you are playing with. Your task is to negotiate the price of each token for both of you (you and the allocator). This means that the price you arrange for the tokens will be valid for both your tokens (the ones the allocator lets you keep) as well as the tokens the allocator is going to keep for herself. In other words, your decision will affect both of you. Either you can sell each token for CHF 1.80. Or you can also make a deal and sell them at CHF 0.60 each. If you do that, you will collect a premium of CHF 6 . To summarize, you (the seller) have to decide what the value of those 20 tokens will be at the end of the experiment. The options are:

Option A: Each token will be worth CHF 1.80.

Option B: Each token will be worth CHF 0.60, and as compensation you will receive CHF 6 only for yourself (plus the value of your tokens).

The allocator will not be able to know if you chose Option A or Option B until after the tokens have been distributed. Additionally, you (the seller) will not know how the allocator distributed the tokens until after you have chosen Option A or Option B. Remember that the experiment is completely anonymous; accordingly, the allocator does not know with whom he is participating. Likewise, you (the seller) do not know the identity of the allocator. When the allocator distributes the tokens, he has no way of knowing which option you are going to choose.

Finally, you need to know that there are two kinds of allocators: those who can move up to 8 of each person's tokens, and those who can move up to 2 of each person's tokens. What you do not know is what kind of allocator you get to play with. 


\section{NOTE: These are the Allocator's instructions, NOT your instructions.}

\section{Examples}

Before you make your decision, let's look at an example:

If the seller chooses Option B (CHF 0.60 per token) and you choose to keep 12 tokens, you would collect:

CHF $0.60 \times 12=$ CHF 7.20

And the seller would collect:

CHF $0.60 \times 8+$ CHF $6=$ CHF 10.80

On the other hand, if the seller chooses Option A (CHF 1.80 per token) and you choose to keep 10 tokens, you would collect:

$$
\text { CHF } 1.80 \times 10=\text { CHF } 18
$$

And the seller would collect:

CHF $1.80 \times 10=$ CHF 18

\section{Comprehension Questions [Allocator - On screen]}

Before continuing, we want to make sure the rules are clear, so we are going to ask you 5 questions. Note that if you answer any of the questions incorrectly, CHF 5 will be deducted from your final payoff.

After answering all the questions, confirm your entries by clicking the "Ok" button. Then, you will directly proceed to the decision screen. 
Before continuing, we want to make sure the rules of the previous experiment for which you just read the instructions are clear, so we are going to ask you 5 questions. Note that if you answer any of the questions incorrectly, CHF 5 will be deducted from your final payoff.

After answering all the questions, confirm your entries by clicking the "Ok" button. Then, you will directly proceed to the decision screen.

We are now going to ask you to make your guesses. On your screen, you now see the exact same instructions as on this page.

Please provide all your answers on your screen in the respective boxes.

\section{Guess 1}

For an additional CHF 6: In your opinion, which of the following two options did a randomly chosen seller in the previous experiment choose? (select the respective box on your screen)

$\square \quad$ Option A: Each token will be worth CHF 1.80.

$\square \quad$ Option B: Each token will be worth CHF 0.60 and CHF 6 for the seller only.

We will compare you answer to the choice made by a randomly chosen seller. If your answer is correct, you will receive an additional CHF 6 as a prize.

\section{Guess 2}

For an additional CHF 6: Out of all the participants who were assigned to the role of the seller in a previous session of the experiment, we calculated which percentage chose option B (CHF 0.60 per token plus CHF 6 for the seller only). In your opinion, what was the percentage of sellers who chose option B?
$\square 0-10 \%$ of sellers chose Option B
$\square 10-20 \%$ of sellers chose Option B
$\square 20-30 \%$ of sellers chose Option B
$\square 30-40 \%$ of sellers chose Option B
$\square 40-50 \%$ of sellers chose Option B
$\square 50-60 \%$ of sellers chose Option B
$\square 60-70 \%$ of sellers chose Option B
$\square 70-80 \%$ of sellers chose Option B
$\square 80-90 \%$ of sellers chose Option B
$\square 90-100 \%$ of sellers chose Option B

If your answer is correct, you will receive an additional CHF 6 as a reward. 
The participants answer the following comprehension questions (on screen):

\section{Comprehension Questions}

1. If, when distributing the tokens, an allocator decides to keep 10 tokens for himself and leave 10 tokens for his paired seller, and the seller chooses Option B (CHF 0.60 per token), how much will each one of them collect (in CHF):

Allocator: Seller:

2. If, when distributing the tokens, an allocator decides to keep 12 tokens for himself and leave 8 tokens for his paired seller, and the seller chooses Option A (CHF 1.80 per token), how much will each one of them collect (in CHF):

Allocator: Seller:

3. Can the experimenter link the decisions made by allocators or sellers in the previous experiment with their names?

$\square \quad$ Yes

$\square \quad$ No

4. Can participants in the previous experiment find out who they are paired with?

口 Yes

$\square$ No

5. Did the seller in the previous experiment know how his allocator distributed the 20 tokens before he chose Option A or Option B?

$\square$ Yes

$\square \quad$ No

\subsection{Survey}

Please answer the following questions:

1. Did you understand the rules of the experiment?

$\square \quad$ I fully understood them

口 I almost fully understood them

- I only partially understood them

口 I did not understand them

2. Would you like to be called for a future experiment?

$\square \quad$ Yes

$\square \quad$ No

3. How old are you?

4. What is your gender?

口 Female 
$\square \quad$ Male

5. As compared to the families of the other students in your university, do you think your family is;

$\square \quad$ Much poorer than the average

$\square$ Poorer than the average

$\square \quad$ As the average

$\square \quad$ Richer than the average

$\square$ Much richer than the average

6. There are currently people who want more income redistribution, and who reject the criticisms of people who say that would be a bad thing (for example, because it would lead to inefficiency in production, inflation, or other problems). Do you agree that the government should redistribute more? I Agree that ...

$\square \quad$ redistribution should be increased a lot

- redistribution should be increased a little

- current redistribution levels should be maintained

$\square \quad$ redistribution levels should be decreased a little

$\square \quad$ current redistribution levels should be decreased a lot

7. What is your field of study (major)?

7. UZH, Faculty of Theology

8. UZH, Faculty of Law

9. UZH, Faculty of Economics, Business Administration, Information Technology

10. UZH, Faculty of Medicine

11. UZH; Vetsuisse-Faculty

12. UZH; Faculty of Arts

13. UZH, Faculty of Science

14. ETH, Department of Architecture and Civil Engineering

15. ETH, Department of Engineering Sciences

16. ETH, Department of Natural Sciences and Mathematics

17. ETH, Department of System-oriented Natural Sciences

18. ETH, Department of Management, Technology and Economics

19. Other

When they are done with the Survey, subjects see the following waiting screen:

You have now finished the experiment. We will shortly begin to call participants one-by-one to come to the cashpoint outside the room to collect their payments. Please note that we will call you based on your seating number (green card). Once it is your turn to leave the room please take all your personal belongings with you. 